\title{
Paracas Cavernas, Topará y Ocucaje, en el origen de los CONCEPTOS: MATERIALES CERÁMICOS DE CERRO COLORADO (excavaciones de Julio C. Tello)
}

\author{
Krzysztof Makowski ${ }^{\mathrm{a}}$ \\ Tomasz Kotomański ${ }^{\mathrm{b}}$
}

\begin{abstract}
Resumen
La historia de los términos "Paracas", "Ocucaje» $y$ "Topará", asi como de las cronologías relativas que les sirvieron de fundamento conceptual, demuestran que sus definiciones respectivas se desprenden del estado de conocimientos y de las metodologias que estuvieron en uso en la época de su formulación. Por una casualidad de la historia, las primeras interpretaciones del "origen" de la complejidad social en la costa sur por Julio C. Tello se fundamentaron en sus excavaciones en la bahia de Paracas (Cerro Colorado-Wari Kayan y Arena Blanca-Cabezas Largas), un sitio en la frontera entre dos áreas culturales diferentes: Topará al norte y Ocucaje-Nasca al sur del valle de Pisco. Las diferencias atañen a las tradiciones tecnológicas alfareras y la arquitectura monumental, entre otros aspectos. Dichas áreas se consolidan como tales después del ocaso de Chavín de Huantar, justo en la transición entre dos periodos que John H. Rowe definiría años después como el Horizonte Temprano y el Periodo Intermedio Temprano. Desde los descubrimientos de Tello, la mayoría de arqueólogos peruanos y europeos optó por llamar Paracas a todas las expresiones materiales del Periodo Formativo pre-Nasca de la Costa Sur en el primer milenio a.C., y asimismo, por considerarlas a priori componentes de una sola cultura, creada por un determinado grupo humano. Los resultados de las investigaciones recientes, incluyendo el análisis del material cerámico de la fase Paracas Cavernas que hacen los autores de este artículo, invitan a la revisión critica de tales interpretaciones. Los especimenes procedentes de las excavaciones de Tello y conservados en el Museo de Arqueología, Antropología e Historia del Perú (MNAAHP) pertenecen a diferentes estilos. Especimenes pertenecientes a tradiciones tecnologicas y estilísticas notablemente distintas fueron registrados por Tello dentro del mismo contexto funerario. Uno de los estilos dominantes se conoce bajo el nombre de Topará (fases Jahuay y Chongos), pero hay también vasijas Ocucaje del valle alto y medio de Ica, asi como una pieza importada del valle del Mantaro. La presencia del estilo Topará en la fase Cavernas brinda argumentos de peso para considerar la peninsula de Paracas como frontera, y como lugar de interacción entre las áreas "Topará»" $y$ "Ocucaje-Nasca». Asimismo, este hecho se suma a varios otros para sugerir plena continuidad entre las fases que Tello consideraba expresiones de dos culturas diferentes, la Paracas-Cavernas y la Paracas-Necrópolis.
\end{abstract}

Palabras clave: Arqueología andina, Horizonte Temprano, Paracas: sitio y cultura, Topara, Ocucaje

a Pontificia Universidad Católica del Perú, Sección de Arqueología, Departamento de Humanidades

Programa Arqueológico-Escuela de Campo «Valle de Pachacamac»

Correo electrónico: kmakows@pucp.edu.pe

${ }^{\mathrm{b}}$ Laboratorio de Arqueología y Conservación, Varsovia, Polonia

Correo electrónico: archeolog@kolomanski.pl 


\section{Abstract \\ PARACAS CAVERNAS, TOPARÁ AND OCUCAJE, AT THE ORIGIN OF THE CONCEPTS: CERAMICS FROM CERRO COLORADO (JULIO C. TELLO'S EXCAVATIONS)}

The story of the terms "Paracas", "Ocucaje» and "Topara'", as well as the relative chronologies that served as conceptual basis for these terms, demonstrate that their definitions emerge from the state of knowledge and methodologies that were in use at the time of its formulation. By an accident of history, the first interpretations of the "origin» of social complexity on the south coast by Julio C. Tello were based on his excavations in the Paracas Bay (Cerro Colorado-Wari Kayan and Arena Blanca-Cabezas Largas), a site located on the border between two different cultural areas: Topara to the north and Ocucaje-Nasca, to the south of the Pisco valley. The differences relate to technological pottery traditions and monumental architecture, among others. These areas are formed as such after the dusk of Chavin, right at the transition between two periods that would be defined years later as the Early Horizon and Early Intermediate Period by John H. Rowe. Since the discovery of Tello, most Peruvian and European archaeologists chose to call "Paracas» all material expressions of the Formative (pre-Nasca) Period on the southern coast at the first millennium BC, and likewise to consider them a priori as components of a single culture, created by a particular group. The results of recent research, including the analysis of ceramics of the "Paracas Cavernas" phase made by the authors of this article, invite to a critical review of such interpretations. Specimens preserved today in the Museum of Archaeology, Anthropology and History of Peru (MNAAHP) belonging to different technological and stylistic traditions were recorded by Tello in the same funerary context. Topara is a dominant style (Jahuay and Chongos phases), but there are also Ocucaje style ceramics from the upper and middle valley of Ica, as well as a piece imported from the Mantaro Valley. The presence of Topara style in the Cavernas phase provides strong arguments to consider the Paracas Peninsula as a border, and a place of interaction between "Topara" and "Ocucaje-Nasca" areas. Also, this fact among others suggests full continuity between the phases that Tello considered expressions of two different cultures, the Paracas-Cavernas and Paracas-Necropolis.

Keywords: Andean archaeology, Early Horizon, Paracas: site and culture, Topara, Ocucaje

\section{Introducción}

En la percepción de los autores, las definiciones de períodos, culturas y estilos se crean a lo largo de la historia de cada arqueología regional, y se desprenden del estado de conocimientos y de las metodologías que estuvieron en uso en la época de su formulación. Son aproximaciones que intentan clasificar las variabilidades de la cultura material, según ciertos criterios que son preestablecidos a priori, y están fuertemente influenciados por la percepción de la cultura material, el urbanismo de la sociedad y de las instituciones políticas del presente. Por ende, puede afirmarse que ni las «culturas arqueológicas", ni los estilos existieron en el sentido histórico en la forma como lo perciben los prehistoriadores y tampoco corresponden necesariamente a «sociedades», "poblaciones» o a etapas que realmente habrían marcado la historia de una región.

El caso Paracas podría considerarse paradigmático para la situación metodológica que acabamos de describir. Varios conceptos claves que proporcionan fundamentos para los discursos interpretativos de la arqueología andina, se han dado encuentro creando cierta confusión y originando asimismo encendidas polémicas concernientes a la terminología y a la cronología relativa. El término «Paracas» fue introducido por Julio C. Tello $(1928,1929,1959)$ y utilizado en referencia a lo que el pionero de arqueología nacional consideraba una «cultura», en su acepción de la cultura matriz, la que crea fundamentos de desarrollo, nace en un foco determinado y se difunde hacia amplios territorios definidos geográficamente. Las características de la cerámica y de los textiles hallados por Tello en la bahía de Paracas y su comparación con las colecciones provenientes del valle de Ica, servían para caracterizar a la hipotética cultura. John Howland Rowe y sus dos alumnos y colaboradores, Dorothy Menzel y Lawrence Dawson (1964) han acuñado el término Ocucaje refiriéndose al conjunto de variables iconográficas, formales y de acabado, que caracterizan a la cerámica encontrada en el valle de Ica (la parte costeńa de la cuenca). Estas mismas variables servirían en la intención de los investigadores para armar una secuencia cronológica maestra que abarcaría 
desde los orígenes del fenómeno Chavín, hasta la consolidación del estilo Nasca. En términos de la secuencia seriada de Menzel, Rowe y Dawson (1964), la cerámica hallada por Tello (1959; Tello y Mejía Xesspe 1979) se ubica en las fases finales, post-Chavín. El nombre del pequeño valle entre Cañete y Chincha - Topará - ha aparecido en la literatura del tema a raíz de las prospecciones y excavaciones de Lanning (1960) y Wallace (1963, 1971, 1985, 1986, sf.), quiénes encontraron evidencias contundentes sobre el estilo de cerámica, diametralmente distinto del Ocucaje, pero hallado por Tello en asociación directa con los fardos Paracas. Ellos han demostrado asimismo que las secuencias preliminares del desarrollo de este singular estilo, las establecidas a partir de las excavaciones en Jahuay (Quebrada de Topará; véase también Würster 1984) y Quebrada (Valle de Cañete) son coetáneas con las dos fases que ha establecido Tello en Paracas (Silverman 1991, 2009).

Las investigaciones posteriores realizadas por los Dwyer (1971, 1975, 1979 a,b), Ann Paul (1980, 1982, 1986, 1990, 1991a) y Ann Peters (2010, 2012 a,b), sobre el material textil proveniente de las excavaciones de Tello y sobre otros componentes del ajuar (Peters 2010), han puesto en evidencia que las características estilísticas e iconográficas Ocucaje, recurrentes en al valle de Ica y las Topará, potencialmente originarios de los valles al Norte de Pisco —Chincha, Topará y Cañete-, se pueden manifestar en los textiles y otros soportes dentro del mismo fardo paracas. Por otro lado, diseños y motivos característicos para el estilo Nasca aparecen en la época inmediatamente posterior al ocaso Chavín siendo registradas en las tres últimas fases de la secuencia de Menzel, Rowe y Dawson (1964). Dichos motivos se presentan tanto en la cerámica decorada con incisiones y pintura poscocción, como en textiles (Silverman 2002a). Cabe recordar asimismo que los autores mencionados pusieron énfasis en el hecho de que su división entre la secuencia del Horizonte Temprano (Ocucaje) y el Período Intermedio Temprano (Nasca), se ha establecido de manera completamente arbitraria a partir del cambio en las técnicas de acabado de cerámica: el uso preponderante de la pintura precocción, antes limitado, sustituye a la compleja técnica de la pintura poscocción empleada durante todo el Horizonte Temprano junto con el negativo.

En el contexto que acabamos de esbozar es menester someter a la crítica el tradicional concepto de la cultura Paracas. El propósito principal de este artículo es demostrar que la presencia de varios estilos en interacción caracteriza a toda la secuencia Paracas, como bien lo han intuido Menzel, Rowe y Dawson (1964). Sin embargo, las fases contemporáneas con el desarrollo de Chavín y las que suceden a su ocaso, tienen características diferentes en tantos aspectos que se debe dudar de la simple continuidad cultural tantas veces evocada en la literatura del tema. Diferentes son también los itinerarios y eventualmente los mecanismos de la difusión de los objetos y de las ideas. La época previa al ocaso de Chavín sorprende por la envergadura de contactos comprobados entre el Norte y el Sur y entre la sierra y la costa (Burger 1988, 1992, 1993 2013; Tellenbach 1999; Dulanto 2015; Kaulicke 2015; Young 2018). En comparación, el período posterior al ocaso del templo de Chavín se caracteriza por las interacciones de carácter regional que involucran a la costa y a la sierra sur y central (Massey 1986, 1991a, b; Reindel 2009; Matsumoto y Cavero 2013). Asimismo, se intensifican los movimientos poblacionales y las redes de intercambio entre las partes bajas y altas de los valles, así como entre los valles interandinos (Reindel 2009; Isla y Reindel 2015). El desarrollo de las redes de intercambio repercute en el aumento de uso de lana de camélido y de obsidiana en la costa (Wallace 1960, 1975, 1979; Conklin 1971, 1978; Burger 2013; Young 2018). Por otro lado, en las fases finales de la secuencia coexisten dos estilos diametralmente distintos. Solo uno de ellos puede ser considerado la continuación de la tradición previa, con raíces en la primera mitad del Horizonte Temprano en cuanto a las técnicas de acabado, pero con innovaciones importantes en el repertorio icononográfico. El otro estilo -Topará (Wallace 1985, 1986, sf; Peters sf., 1986, 1989-88; Silverman 1991, 1995, 2009; Makowski 2001, 2004, 2010) o Paracas-Necrópolis (Tello 1959; Tello y Mejía Xesspe 1979)—, es inovativo en todos los aspectos, tanto en la tecnología alfarera, como en las formas y acabados. Cada uno de los dos estilos alfareros se relaciona con manifestaciones culturales diferentes en comparación con el otro. Este es el caso, por ejemplo, de 
arquitectura o de textiles. Es más, los recientes hallazgos de Tantaléan et al. $(2013,2018)$ y Nigra (2017), sugieren que hay una relación directa entre la aparición del estilo Topará (fase Jahuay) y el abandono definitivo de los complejos monumentales típicos para Paracas Medio en el valle de Chincha, antes erróneamente atribuidos a Paracás Tardío (Necrópolis: Canziani 2012, 2015). Por otro lado, existe casi un consenso en la literatura del tema, sobre que el avance de la tradición Topará en sus diferentes expresiones materiales, desde el Norte hacia al Sur, guarda estrecha relación con la formación de la cultura Nasca. En el contexto de discontinuidades y complejidades que caracterizan el período hoy denominado Paracas Tardío (Período Horizonte Temprano 8-10), y que fueron insospechadas hace 100 años cuando Julio C.Tello excavaba en las orillas de la bahía de Paracas, se impone hacer la pregunta, si la época de Paracas Cavernas, hoy asignada al Período Paracas Tardío, debe ser entendida como un etapa más en el desarrollo de la misma «cultura» de la costa sur, o se trata de un período marcado por importantes cambios sociopolíticos, religiosos y tecnológicos sin, o con pocos antecedentes previos. Desde la perspectiva actual, resulta improbable el orden social y la organización territorial imperante en el Período Paracas Tardío, se haya podido desarrollar de las condiciones vigentes en los Períodos Paracas Temprano y Medio, los que están inmersos en el contexto del auge de Chavín de Huantár (Kaulicke 2015).

\section{Paracas: cultura y estilo}

El sitio de Paracas, en la península de este nombre, cercana al valle de Pisco, fue probablemente localizado por un huaquero de nombre Juan Quintana, alias «sordito», entre 1905 y 1907, quien posteriormente trabajara para Domingo Cánepa, coleccionista de Pisco (Paul 1991: 5). Desde 1911, los textiles de Paracas aparecieron periódicamente en el mercado de antigüedades, pero con supuesta procedencia de Ica/Nazca. A partir de 1914, Tello tuvo la oportunidad de conocer y estudiar varias colecciones de piezas Paracas, pero recién en 1925 logró llegar al sitio, acompañado de Samuel Lothrop y Toribio Mejía Xesspe, y guíado por el huaquero mencionado (Daggett 1991:16). Entre 1925 y 1930 (Tello 1959; Tello y Mejía Xesspe 1979; Tello 2009: 206, 207) Tello y sus colaboradores excavaron tres áreas, dos en Cerro Colorado y una en las lomas adyacentes a la playa (Arena Blanca). La excavación de la tercera terraza fue iniciada por el equipo de Tello, pero continuada por Yacovleff y Muelle (Muelle 1931; Yacovleff 1932). Durante estos trabajos se encontraron en la cima de Cerro Colorado entierros múltiples dentro de cámaras expresamente cavadas en la roca y accesibles a través de un pozo tubular que lleva a una bóveda (Tello 2009, 2012: 221-230). La particular forma de arquitectura funeraria fue denominada por Tello «caverna». Los entierros en las dos áreas restantes tuvieron un aspecto diferente. Aunque se trataba también de fardos que contenían individuos sentados con los miembros fuertemente flexionados, estos se ubicaban dentro y fuera de estructuras rectangulares subterráneas de piedra. Tello, de manera equivocada, atribuyó a estas estructuras la función de mausoleos, por lo que el cementerio entero mereció, a su juicio, el nombre de «Necrópolis». Tello (1929: 29), escribe así sobre el área: «Aunque a primera vista todo haría pensar que se trata de una población compuesta de viviendas, cocinas y patios, cuando se abren las grandes cámaras funerarias contiguas a ellas, y se constata la presencia de cadáveres ricamente engalados y de hornos crematorios, es sólo entonces que se comprueba que todos los edificios están subordinados a la cámara funeraria» (Tello 1929: 129). Este comentario fue formulado a propósito del asentamiento de Arena Blanca, llamado también Cabezas Largas, pero la misma opinión merecía el cercano Wari Kayan (Tello 1959). Años después de la muerte del gran arqueólogo peruano, Mejía Xesspe (Tello y Mejía 1979: 251-263), tendría que desmentir esta apresurada impresión del primer momento. En realidad, las estructuras rectangulares cumplían función de depósitos, se relacionaban con la ocupación doméstica anterior, y fueron reutilizadas para fines funerarios (Mejía Xesspe 1979: 304-315; Engel 1966; Tello). Es menester recalcar que los entierros dentro de los espacios arquitectónicos constituían solo un porcentaje de la totalidad. 
En las dos terrazas de la cima, Tello y Mejía (1979: 100-261, figs. 8, 13, 17) reconocieron, entre intactos y disturbados por huaqueros, 75 entierros individuales (algunos convertidos en múltiples a raíz de reapertura), en pozos cavados dentro del suelo de 70 a 300 centímetros de profundidad, y solo ocho cámaras, "cavernas» que contenían entre 3 y 37 individuos cada una. La excavación de la tercera terraza fue iniciada por el equipo de Tello, pero continuada por Yacovleff y Muelle (1934). En las dos otras áreas los fardos sepultados dentro de los depósitos subterráneos reutilizados para este fin no llegan ni a 10\% de la totalidad (Tello y Mejía 1979: figs. 86, 87; Tello 2009: 206, mapa). A pesar de ello, la aparente relación entre las formas arquitectónicas y los estilos de alfarería y de textiles encontrados en los fardos sugestionaron a Tello a tal punto que acuñó para sus fases los términos Paracas Cavernas y Paracas Necrópolis.

Es imposible entender a cabalidad el significado que los descubrimientos en Paracas tuvieron para Tello mismo, y, por ende, el alcance real de los dos términos cronológicos, sin recordar sus planteamientos generales. Todos los trabajos arqueológicos de Tello fueron en algún grado subordinados a un objetivo general. Pretendía a través de ellos, comprobar la validez de su propuesta alternativa a la alóctona de Uhle sobre el origen de la civilización andina (Tello 1942, 1959; Ravines 1970; Burger 2009). La civilización se origina, según Tello (1929: 17-26; 1967: 61-65), en los Andes Orientales colindantes con la floresta cuyo clima tropical favorece el crecimiento de la mayoría de ancestros silvestres de las plantas domesticadas posteriormente. El culto al jaguar, a la serpiente y la caza ritual de cabezas-trofeo son, para él, relictos de la época de origen. No obstante, la civilización puede desarrollarse plenamente solo en la sierra, en el medio natural que constituye un reto para la imaginación y la habilidad humana, verbigracia, sistema de riego y andenería, y de dónde provienen los cultígenosrestantes, así como los camélidos domesticados. La fusión de los conocimientos y de las tecnologías adquiridas en la floresta y en la sierra, hace posible la colonización del desértico e inhóspito medio de la costa. El desarrollo de la civilización andina se realiza para Tello en cuatro estadíos que él llama épocas y numera de I a IV. Estas mismas épocas conforman los períodos en su cronología relativa general para los Andes. En la primera época los pueblos agricultores procedentes del Oriente colonizan el área centroandina y las experiencias culturales de la floresta y de la sierra se amalgaman de manera creativa en el seno de la primera gran civilización, matriz para todas las siguientes, la civilización Chavín. La segunda civilización es fruto de procesos de integración en la sierra de los Andes occidentales donde nuevos aportes desde las periferias se sobreponen al substrato Chavín: «poblaciones construidas en su mayor parte en los sitios mas encumbrados, tumbas en cámaras de piedra..., alfarería de formas globulares, pintadas a color perdido (...o negativo..), bícromas o polícromas, desarrollo extraordinario del arte textil, a base del algodón en el norte y de la lana en el centro y sur, y de los tintes de origen vegetal..." (Tello 1967: 62,63) son algunas de las expresiones de la segunda civilización, enumeradas por Tello. "Se comprenden en esta época», escribe, "la Cultura Andina propiamente dicha, apenas regionalmente diferenciada en el Norte, Centro y Sur, con Tiahuanako como su más alto exponente, y las grandes culturas del Litoral: Tallán y Muchik al Norte y Nasca al Sur» (Tello 1929: 25). La tercera civilización se origina en el litoral del Pacífico y la cuarta es el producto del Imperio Incaico. La complejidad de las estructuras políticas y el supuesto grado de consolidación étnica son los criterios que utiliza Tello para diferenciar estas dos últimas épocas de su secuencia. En la tercera, las etnias se transforman en naciones, preparando las bases para la gran integración del tiempo del Tahuantinsuyu.

Paracas juega un papel protagónico en el modelo de Tello, quien cree que en el sitio se refleja la historia de su Primera Época y la transición hacia la Segunda. Es la época más importante puesto que se originan en ella todos los contenidos religiosos y la mayoría de las características de la civilización andina. La cultura Paracas Cavernas tiende el puente necesario entre las dos expresiones tempranas de la civilización en la sierra: Chavín en el norte y Pucará en el sur. Sus supuestas características coinciden con las expectativas de Tello. Por un lado, la importancia de los recursos marinos, la sencillez de las telas burdas y el carácter relativamente simple de los entierros parecen brindar la 
prueba esperada del relativamente bajo nivel de desarrollo de la costa en los tiempos en que, en la sierra, el templo de Chavín recibe miles de fieles. Por otro lado, todos los productos más sofisticados, como las telas decoradas y la cerámica incisa y pintada con pigmentos resinosos, contienen rasgos estilísticos que los vinculan directa o indirectamente con el fenómeno Chavín. Así parece comprobarse el rol civilizatorio de la sierra.

La verdadera civilización llega, sin embargo, a las costas de Paracas, en la visión de Tello (op.cit.), recién con el esplendor de las grandes Necropolis de Wari Kayan y Cabezas Largas. Los portadores de la cultura de Paracas Necrópolis tienen para Tello todos los rasgos de los hijos de la Segunda Epoca: soberbios guerreros, ataviados de plumas de aves de la Costa y de la Selva y de textiles bordados multicolores. La cerámica monocroma, a veces decorada con negativo, contrasta con la policromía de tejidos de lana bordados y teñidos con tintes importados. El estilo Nasca encuentra el antecedente inmediato en la decoración de estas telas. El culto al felino, característico para Chavín persiste, pero queda subordinado a las divinidades de aspecto antropomorfo. Para Tello este ha sido uno de los indicios más relevantes de la transición hacia la civilización. Conforme con las premisas de su modelo, Tello resalta las diferencias entre las culturas Paracas Cavernas y Paracas Necrópolis en todos los niveles, incluyendo los rasgos antropológicos y las deformaciones craneanas. Insinúa de este modo que los portadores de la civilización que llegan en la fase Paracas Necrópolis son étnicamente distintos de los pescadores Paracas Cavernas. Años después de la muerte del maestro, su compañero y discípulo, Toribio Mejía Xesspe (Tello y Mejía Xesspe 1979: 214), tratará de matizar esta posición e insinuará que ambos grupos representaban a la misma cultura.

La propuesta de Tello influenció los estudios posteriores sobre el Horizonte Temprano y Período Intermedio Temprano en dos aspectos centrales: 1. Se aceptó la premisa de que el desarrollo de la Costa Central y Centrosur se debe a la difusión de la cultura Chavín, y 2. La denominación Paracas (Cavernas) quedó reservada para definir las expresiones culturales del Horizonte Temprano en las áreas mencionadas, lo que se desprendía del esquema tripartito de Tello, Norte-Chavín, CentroParacas, Sur-Pukará.

El auge de estudios sobre la Costa Centrosur se inicia después de la muerte de Tello en 1947, particularmente en la década de los cincuenta. Rowe, Menzel y Dawson, realizan prospecciones en el valle de Ica y estudian las colecciones de cerámica procedente del valle. Donald Lathrap y Edward P. Lanning descubren el sitio Jauhay en la quebrada de Topará (Lanning 1960; Wallace 1963, 1971, 1986), Frederic Engel (1987) y Edward P. Lanning (1960) trabajan en Carhuas y Cabezas Largas, Jorge Muelle excava en Chuccho y Carhuas, Dwight Wallace (op. cit.) en el sitio los Patos en Cañete y Chongos en Pisco. La cantidad de información sobre los estilos cerámicos reunida a raíz de estos proyectos era considerable (véase la historia de investigaciones en: Paul 1991). Los resultados parecían confirmar en puntos esenciales la cronología general trazada por Max Uhle (1913; Reindel et al. 2010), Alfred Kroeber (1944, 1953), Anna Gayton (Gayton y Kroeber 1927), Julio C. Tello (1959) y Wiliam D. Strong (1957). En particular, se reforzaba con nuevos argumentos la idea de que cíclicamente ciertos estilos, a saber, Chavín, Wari-Tiahuanaco e Inca, se hayan difundido a través de todos los Andes Centrales creando el efecto de horizontes. Rowe (1961, 1962a, b, 1967b) la fundamentó con un marco teórico moderno y propuso la conocida cronología relativa que está actualmente en uso. Su propuesta de diferenciar un período inicial, tres horizontes y dos períodos intermedios recibió la sustentación empírica en la secuencia cerámica elaborada para el valle de Ica por él mismo, Menzel y Dawson. La cronología del estilo Ocucaje en el valle de Ica adquirió de este modo un peso mucho mayor de lo que se desprendería de la real relevancia de este estilo en la escala andina y regional; asumió el papel de la secuencia matriz, por lo que constituyó durante los últimos treinta años el punto de referencia obligado de los fechados relativos para todos los Andes peruanos. En consecuencia, la definición cronológica y espacial de la cultura Paracas quedó amarrada de manera más fuerte aún a la de la cultura Chavín. 
Menzel, Dawson y Rowe (1964) construyeron su seriación a partir de una amplia muestra que comprendía: los fragmentos cerámicos recogidos de la superficie de sitios, así como procedentes de las excavaciones del sitio Cerrillos por Wallace (1962), las piezas enteras en las colecciones de Pablo Soldi, Paul Truel y Aldo Rubini en Ica, analizadas por Dawson, y los ceramios encontrados por Strong (1957), durante sus excavaciones en los cementerios prehispánicos de Ocucaje; varias piezas de calidad excepcional en las colecciones de Estados Unidos y de Europa completaron la serie (Rowe 1958). Este material fue analizado de manera muy detallada en cuanto a las características formales de las vasijas. Un peso especial fue otorgado a los rasgos concernientes a la iconografía y al estilo de la decoración. Sobre un total de 461 características diferenciadas por Menzel, Rowe y Dawson, $7.6 \%$ se refiere a las formas de vasijas y otros $4.8 \%$ a las técnicas decorativas ${ }^{1}$. Las $87.6 \%$ restantes describen la variabilidad, que se percibe, según ellos, en el repertorio de motivos iconográficos y en las variantes de representación. Los autores de la secuencia asumieron: 1) Que las vasijas decoradas con los motivos comparables con la litoescultura de Chavín de Huántar (Rowe 1967 a) son las más tempranas, mientras que las más tardías se asemejan en diseños a las vasijas Nasca, y 2) Que entre una y otras se extienden fases intermedias de paulatina transformación.

Conforme con las premisas expuestas, el material cerámico fue ordenado por grupos y descrito según el listado de rasgos conformando una matriz de variabilidad. La presencia y/o la ausencia de ciertos rasgos reflejaba el grado de similitud entre las piezas y asimismo expresaba la distancia que separaba a todo el grupo de las características Chavín, si el grupo se situaba en la mitad superior de las filas de la matriz, o de las características Nasca, si, por el contrario, el grupo se situaba en las filas de la mitad inferior. La particular geografía del valle de Ica fue tomada en cuenta por los autores. El río tiene poca agua, por lo que se seca antes de llegar al mar y forma en la costa una cuenca de diseño caprichoso. En el curso medio-alto, el valle de Ica se acerca al valle de Pisco y recorre de Este - noreste a Oeste- Suroeste, pero en la desértica costa cambia en dirección Norte-Sur y se acerca al sistema hidrográfico del río Grande de Nazca. Una serie de amplios oasis, hoyas, algo distanciadas unas de otras, se forma en esta parte: Ocucaje, Callango, Ullujaya, Samaca. Los oasis se benefician por el alto nivel de la napa freática. El ecosistema dependía del grado de cobertura boscosa de huarangos (Prosopis sp.), como lo demostró recientemente Beresdorf-Jones (et al. 2010[2009]). Los autores de la secuencia matriz asumieron que cada segmento del valle de Ica pudo conocer un desarrollo estilístico ligeramente distinto, y para algunas fases trataron por separado el material cerámico procedente de diferentes unidades geomorfológicas: valle medio y alto, arriba de la ciudad de Ica; valle medio, entre la ciudad de Ica y la hoya de Ocucaje; valle medio bajo, con las hoyas de Ocucaje y Callango. En la fase 8 separaron también el material procedente de las dos hoyas mencionadas.

Como resultado obtuvieron 16 grupos de ceramios correspondientes a supuestas 10 fases cronológicas. En las primeras dos fases agruparon un número muy reducido de piezas de las colecciones, supuestamente procedentes de Ocucaje, y caracterizadas por la presencia de asa estribo y de una cara de felino, relativamente realista, en relieve. Ambas características son norteñas. Las fases 3 y 4 se organizan alrededor del material cerámico procedente de las excavaciones $\mathrm{y}$, a diferencia de las anteriores, están bien respaldadas por numerosas piezas en el característico estilo Ocucaje, que se distingue por el uso de pintura multicolor resinosa. La pintura es aplicada sobre la superficie de la vasija después de la cocción, rellenando los campos resaltados con incisiones. La forma de botella con asa puente que une el pico con la protoma figurativa es la más popular y suele recibir una decoración cuidadosa. El seguimiento del motivo de felino difundido en todas las 10 fases con 30 variables (op. cit.: 268-269; véase también Sawyer 1972) como cara (fases 1-8), o cara de frente y cuerpo de perfil (fases 9, 10), cumplió claramente un rol central en el pre-ordenamiento de la serie. En las fases 3 y 4 en la cara del animal se resalta aún rasgos propios de la representación del jaguar mítico en el arte Chavín y Cupisnique, particularmente dos pares de colmillos cruzados. La serie correspondiente a las fases 5 a 8 ha sido ordenada de tal manera que la cara del felino pierde gradualmente el aspecto realista (fase 5), adoptando formas geométricas, hasta convertirse en una 
franjaestilizada de dientes; los ojos, nariz y orejas están transformados en otra franja sobrepuesta (fases 6-8). En la fase 8 la imagen estilizada de jaguar queda remplazada por una representación del felino de las pampas (Felis colocolo), cuya cara carece de fauces visibles y cola. En líneas generales el advenimiento de la fase 8 significa una notable ruptura en la tradición. Cambia el repertorio iconográfico y aparecen motivos nuevos como un ser antropomorfo con la cara acorazonada y ojos compuestos de varios círculos concéntricos, a menudo provisto de algunos rasgos de felino. El cuchillo y la cabeza trofeo son sus atributos más frecuentes. Los ojos del personaje constituyen un rasgo resaltante por lo que se ha acuñado el término Ser Oculado (Oculate Being) para definirlo. Otro cambio, más fuerte aún acontece en la última fase (fase 10). El uso de engobe crema y de pintura aplicada antes de cocer la vasija y una serie de formas nuevas de recipientes cerámicos, refleja la influencia creciente de la tradición Topará. El repertorio iconográfico se amplía considerablemente, incluyendo motivos que aparecen tanto en los textiles Paracas Necrópolis como en la cerámica Nasca Inicial (Nasca I), verbigracia cóndor y otras aves, el depredador marino que posee rasgos corporales de ballena orca y/o tiburón.

\section{La cronología en debate}

Las nuevas evidencias y los nuevos enfoques acumulados durante los últimos quince años han revelado la existencia de una realidad mucho más compleja de la que se desprendía de las síntesis e intuiciones de Tello $(1929,1959)$ y de las meticulosas seriaciones estilísticas de Menzel, Rowe y Dawson (1964). En primera instancia, un panorama completamente nuevo se abrió en cuanto a las relaciones entre los componentes culturales denominados Paracas y Topará en las fases finales del Horizonte Temprano. Este nombre de la quebrada seca localizada entre Chincha y Cañete fue escogido por Edward Lanning (1960: 397) y Dwight Wallace (1963) para denominar el estilo de cerámica monocroma que acompaña a los fardos Paracas Necrópolis, pero cuyos antecedentes se localizaban al parecer en los valles al Norte de la península; tal conclusión se desprendía del análisis del sitio estratificado Jahuay en la quebrada de Topará y de materiales contemporáneos recogidos de la superficie. Los posteriores estudios de Dwight Wallace (1986) y los trabajos de campo de Luis G. Lumbreras y José Canziani (Canziani 1992), Wolfgang Würster (1984), Ann Peters (1987/88), así como más recientes de Ann Peters (2010, 2015), Helaine Silverman (1996, 1997, 2009), Rubén García, José Pinilla y Fernando Herrera (García y Pinilla 1995), Kevin Hill, Ben Nigra, Henry Tantaleán y Terrah Jones (2012) demostraron la considerable envergadura de la ocupación Topará en los valles de Cañete, Chincha y Pisco. La tradición Topará se consolidaría de acuerdo a estas investigaciones entre las fases 8 y 9 del Horizonte Temprano y se desarrollaría de manera autónoma sin interrupción hasta el fin de la fase 2 del Período Intermedio Temprano expandiéndose hacia el Sur, hacia los valles de Ica, Palpa y Nazca (Wallace 1986; Peters s.f., 1997; Massey 1986, 1992; Silverman 1991: 350-380, fig. 9.2; Isla y Reindel, este volumen).

Recientemente, las excavaciones en la Huaca Soto (Nigra 2017), así como en el Cerro del Gentil, El Mono y la Cumbe (Tantaléan et al. 2015, 2018) han puesto en evidencia que, contrariamente a lo esperado, la construcción de imponentes edificios ceremoniales de planta rectangular, orientados este-oeste, no se debe atribuir a los productores de la cerámica Topará (Canziani 1992, 2013), sino a las poblaciones usuarias de estilos Pinta y de otros variantes locales de Paracas, eventualmente comparables con los de Ocucaje de las fases 5-8 del Horizonte Temprano. La cerámica Jahuay 3 y Chongos está presente, en cambio, en los contextos de re-uso de los sitios ceremoniales para otros fines, residenciales y funerarios. En la luz de las investigaciones mencionadas quedó claro que a partir de las fases 8 o 9 del Horizonte Tardío, dos poblaciones con habitos diferentes en cuanto a la producción de cerámica y construcción de edificios públicos se refiere (la paracas y la topará), convivían en la costa centro-sur entre los valles de Cañete y Nazca. El origen y la secuencia del estilo Topará es aún materia de debate, en vista de que ni Peters (2015) en el valle de Pisco, ni 
Nigra (2017) en el valle de Chincha, han logrado encontrar sitios o niveles de ocupación relacionados con la cerámica Jahuay 1 y 2.

Las notables diferencias entre los estilos dominantes que se desarrollan en los valles vecinos, así como los fundamentos estratigráficos relativamente endebles de la secuencia del Horizonte Temprano sembraron sospechas acerca de su valor real como secuencia maestra.

Entre 1980 y 1982 Sarah Massey (1986, 1991a, 1991b, 1992) realizó un programa de investigaciones con sondeos en el valle alto de Ica y propuso una revisión de la secuencia seriada. Todo el material cerámico que logró reunir proviene de sitios prospectados con una metodología uniforme y cubriendo la totalidad del espacio del valle, salvo las hoyas de Ullujaya y Samaca. Massey no encontró sitios o áreas asignables a las fases 1, 2, 5, 6, 7 de Paracas Ocucaje, según la propuesta de Menzel, Rowe y Dawson. Los tiestos con características propias de estas fases, cuando eventualmente aparecen, siempre están asociados a otro componente predominante. Por ello Massey ha sugerido que la secuencia del Horizonte Temprano se inicia en la fase, 3 con un estilo de matiz local, pero influenciado por las tradiciones procedentes del Norte ${ }^{2}$. Massey observa que todos los sitios con material característico para las fases 3 y 4 continúan ocupadas en la fase 8 sin que se perciba entre ellas un momento de abandono o algún estadío intermedio que justifique la presencia de las fases 5, 6 y 7. En cambio la transición entre las fases 8 y 9 está relacionada con profundas transformaciones, tanto en el patrón de asentamientos como en el estilo y en la iconografía: el motivo del felino queda desplazado por el Ser Oculado. Una importante ruptura en la continuidad cultural separa las fases 9 y 10 . Todos los centros regionales y subregionales quedarían abandonados. La uniformidad formal y tecnológica de la cerámica doméstica, mayor que en las fases anteriores, contrasta con la diversidad de la cerámica ceremonial hallada en los entierros de Ocucaje. Los cambios tecnológicos y estilísticos parecen tener origen en la difusión de la tradición Topará. La influencia de esta tradición se incrementa aún más durante las fases 1 y 2 del Período Intermedio Temprano, en las que eclipsa por completo a la tradición Paracas. El subsiguiente cambio en la secuencia, no menos profundo que el anterior, se relaciona con la aparición del estilo provincial denominado Carmen durante la fase 3.

Lisa DeLeonardis $(1997,2005)$ llegó a conclusiones en buena parte similares a partir del análisis de los materiales de superficie recolectados de manera sistemática entre 1988-1990 por Anita Cook, en 26 asentamientos de la hoya de Callango. DeLeonardis (1997:122) pudo definir sin dificultades las muestras correspondientes a las fases 8, 9, 10 En estos tres casos también se ha confirmado la existencia de variables particulares que posee el subestilo de Callango, respecto a Ocucaje y al valle medio. Es menester destacar el aparente abandono de la iconografía característica de las fases 7 y 8 en la fase 9, salvo los motivos de felino, ave y zorro. Aparecen en cambio motivos nuevos, propios al estilo Nasca: apéndice serpentiforme y cabeza trofeo. En la fase 10 todo el repertorio decorativo cambia. De las fases anteriores del Horizonte Temprano, solo la fase 3 estaba bien representada y su definición no causó problemas. Más recientemente, Bachir Bacha y Llanos (2015; Bachir Bacha 2018) han definido tres fases de ocupación en el complejo Animas Altas-Animas Bajas, que cuenta con más de cien estructuras, la mayoría de carácter ceremonial. La fase más antigua se relaciona con la cerámica Ocucaje 8, con escasa presencia de rasgos Ocucaje 7. La mayor parte de edificaciones, entre residenciales de materiales perecibles y ceremoniales, construidas de bloques de greda, se relaciona, sin embargo, con las fases 9 y 10 de Ocucaje, sin que se haya podido, hasta el presente, definir un nivel estratigráfico claro del fin de la fase 9 y el comienzo de la 10. Por el contrario, los materiales se presentan mezclados. Los resultados de las recientes investigaciones de David Beresdorf-Jones (Beresedorf et al. 2010[2009] completaron el panorama del valle de Ica bajo en el Horizonte Temprano, con evidencias concernientes a las hoyas de Samaca y Ullujaya. Los sitios investigados provienen de la fase 3-4 del Horizonte Temprano. En esta época, la hoya parece haber sido aprovechada para asentamientos estacionales y el cultivo de algodón. En todo caso, la presencia humana no afectó los extensos bosques de huarango, los cuales fueron objeto de la tala 
indiscriminada durante el Período Intermedio Temprano, para extender la frontera de cultivos agrícolas, y como material de construcción y leńa. El uso intensivo de suelos para fines agrícolas se iniciaría en las dos hoyas a partir de la fase 9 del Horizonte Temprano, de manera coincidente con el auge de centro ceremonial de las Animas (Bachir Bacha y Llanos 2018).

Las excavaciones llevadas a cabo en la parte alta del valle de Ica y en el vecino valle de Palpa han proporcionado nuevas evidencias estratigráficas que apoyan la cronología de Menzel, Rowe y Dawson (1964). Dwight Wallace y Mercedes Delgado (Wallace et al. 2005; Splitstosser et al. 2010[2009]) han vuelto a realizar excavaciones, esta vez en mayor escala, en el sitio de Cerrillos. Se ha comprobado una notable continuidad en el uso del espacio ceremonial a lo largo del Horizonte Temprano. Las dos primeras fases en la historia del edificio de adobes, construido contra la pendiente del cerro, creando terrazas y escaleras monumentales que llevaban a la cima, corresponden a las fases estilísticas 1 a 5 de la seriación de Menzel, Rowe y Dawson (1964). Splitstosser (et al. 2010[2009]) y sus coautores los agrupan dentro de su Período Paracas Temprano (1000-600 a.C.). A Paracas Medio (fases 6, 7, 8 del Horizonte Temprano, aproximadamente 600-400 a.C.), le corresponde tres modificaciones más que implicaron la construcción de nuevas terrazas en la cima, pero sin cambiar el eje de la escalera. El edificio fue luego sellado con más de sesenta niveles de revoques de barro. El área fue reocupada durante la fase 9 del Horizonte Temprano, pero con arquitectura distinta en cuanto al plano y al carácter. Es menester poner énfasis en esta falta de continuidad entre la secuencia contemporánea con la época de auge de Chavín de Huántar y los períodos posteriores a su ocaso.

Las excavaciones y prospecciones llevadas a cabo con rigurosidad ejemplar por Markus Reindel y Johny Isla (Isla et al. 2003, Reindel e Isla 2008[2006]; Reindel 2009: Reindel e Isla 2010[2009]) en el valle de Palpa, han aportado nuevas pruebas estratigráficas que sutentan la seriación de Menzel, Rowe y Dawson (1964). Aún más relevantes resultaron las pruebas de que en el valle de Palpa se encuentran vestigios ocupacionales Paracas correspondientes a toda la secuencia del Horizonte Temprano, hecho que fue puesto en duda anteriormente (Browne y Baraybar 1988; Browne 1992; Silverman 1994a, 1995). En el sitio Jauranga se han documentado ocupaciones de carácter residencial sobrepuestas desde la fase 5 hasta la fase 8 (Reindel 2009; Reindel e Isla 2010[2009]). Adicionalmente se han excavado numerosos contextos funerarios, seis entierros de Paracas Temprano (Ocucaje 3) en Mollake Chico y en Pernil Alto, otros seis de Paracas Medio (Ocucaje 5, 6, 7) y 50 de Paracas Tardío (Ocucaje 8) en Jauranga.

\section{El fenómeno del Horizonte Temprano, los estilos Paracas y Topará y la cronología absoluta}

Los fardos Paracas se cuentan entre los primeros contextos fechados con el método de radiocarbono en la historia de la arqueología, hecho que ocurrió ya en 1949 (Ziólkowski et al.1994). Estas primeras fechas (Paul 1991 a) brindaban argumentos a favor de la tesis de que las influencias desde el área de la cultura Chavín fueron decisivas para el desarrollo de los estilos Paracas y Ocucaje durante la mayor parte de la secuencia (Ocucaje I-8). Burger (1984, 1985, 1988, 1992, 1993) ha demostrado con sólidos argumentos que, en la segunda mitad de la secuencia del Horizonte Temprano, en la definición de Rowe y sus colaboradores, se habían incrementado notablemente los contactos entre el famoso centro ceremonial en las orillas del Mosna, por un lado, y la costa y la sierra sur, por el otro. Las rutas de intercambio de obsidiana (Burger 2013 inter alia; Young 2018) tuvieron un papel particularmente importante. Estos contactos estuvieron previamente insinuados también, y de manera contundente, por la iconografía de los textiles de colecciones privadas, los que supuestamente fueron hallados en la Peninsula de Paracas, en Carhua (Wallace 1975, 1979; Cordy Collins 1976, 1977). Su análisis desde el punto de vista tecnológico (Wallace 1991) e iconográfico (Cordy Collins 1979 a, b, 1980, 1983; Roe 2008) ha puesto en evidencia que no se trata de imitaciones de la litoescultura de Chavín. Todo lo contrario. Los artesanos que han tejido y decorado las telas representaban diferentes tradiciones locales y foráneas. Algunos de ellos eran capaces de crear 
a la imagen de la deidad con cuerpo híbrido de águila y de felino (Roe 2008), con un buen entendimiento de las reglas complejas de composición Chavín. Otros, en cambio (Cordy Collins 1979 b, 1983) se servían solo de algunas convenciones para diseñar la imagen de una diosa del algodón, personaje que no se conoce del repertorio de Chavín de Huántar, ni tampoco está registrado en el ámbito cultural Cupisnique. La complejidad y la intensidad de las relaciones entre la costa centrosur y el Norte del Perú durante el primer milenio a.C. fue demostrada también por medio de un meticuloso análisis comparativo de las formas enteras de cerámica decorada (Tellenbach 1998). En los últimos años se han sumado hallazgos aún más reveladores. Un centro ceremonial hallado recientemente en las alturas de Ayacucho, se caracteriza por una arquitectura de piedra marcada por influencias Chavín, y los contactos con la sierra norte se expresan también en el material cerámico (Matsumoto y Cavero 2013). En cambio, en el valle de Nazca, aparecieron textiles decorados similares a los de Carhua (Kaulicke et al. 2010[2009]). Las excavaciones recientes de Dulanto (2015) en Puerto Nuevo han brindado evidencias claras de contactos estrechos entre los pobladores de la Peninsula de Paracas y la Costa Central, norcentral, Norte e incluso extremo Norte.Todas estas evidencias brindan un nuevo sustento a la idea de que, sin el fenómeno de Chavín, y sin el efecto «horizonte» que este fenómeno produce, no es posible entender los procesos culturales en la costa centro-sur del Perú durante una parte de la larga secuencia del Período Formativo.

No obstante, ha habido cambios relevantes en la cronología absoluta referente al período definido por la amplia difusión de variables formales y de acabado propios al estilo Janabarriu (Burger 1984) y también al estilo Cupisnique (Tellenbach 1998). Estos cambios repercuten en la definición del tiempo de inicio y del fin del Horizonte Temprano. Las evidencias de mayor relevancia provienen de Chavín de Huantar mismo. Se ha calibrado una extensa serie de fechados provenientes de contextos excavados (Rick et al. 2010) y también de muestras orgánicas (Rodriguez et al. 2013). La cantidad de fechados y las asociaciones directas con los contextos arquitectónicos, previamente analizados con el fin de definir la secuencia constructiva, está paliando en algún grado las distorsiones causadas por la curva plana de calibración, conocida como la Meseta Halstatt. Las dos series de fechados arriba mencionadas son coincidentes en cuanto a la determinación de los períodos de fundación, ampliación y abandono del edificio del Templo. El auge del templo que corresponde a la mayor actividad de construcción corresponde al período entre 900 y 500 cal. a.C. El abandono definitivo ha ocurrido en el trascurso del siglo $\mathrm{V}$ y luego el área fue ocupada por la población portadora de la cerámica perteneciente a la tradición Blanco sobre Rojo, estilo Huará.

Estas fechas invitan a emprender una nueva evaluación de las relaciones entre Chavín y Paracas, en particular para las fases definidas por Julio C. Tello en el sitio epónimo. La larga serie de fechados proveniente de contextos arqueológicos primarios obtenida por Reindel (2009) en Palpa es de gran utilidad para este fin. En las secuencias comparadas de los valles de Ica, Palpa y Nazca se separan con bastante claridad tres períodos pre-Nasca Inicial (Ocucaje 10-Nasca 1, 2: Reindel 2009): Temprano (Ocucaje 3, 4), Medio (Ocucaje 5, 6, 7), Tardío (Ocucaje 8, 9). Según Unkel y Kromer (2009) el Período Paracas Temprano abarca en Palpa aproximadamente tres siglos, entre 800-550 a.C. y coincide con el auge del templo de Chavín de Huántar (compárese con Rodriguez et al. 2013). El Período Paracas Medio (550-370 a.C.) corresponde al confuso período del ocaso y abandono del templo. El Paracas Tardío con el material Ocucaje 8 abarca el período 370-200 a.C. El Nasca Inicial (Ocucaje 10-Nasca 1, 2) tiene fechas entre 120 a.C. y 90 d.C. En este mismo tiempo se inicia la construcción de Cahuachi, famoso centro ceremonial de la cultura Nasca, a juzgar por la nutrida serie de muestras de contextos arquitectónicos analizada por los colaboradores de Giuseppe Orefici (Ziolkowski et al. 1994). Hace falta por supuesto actualizar la calibración de estas últimas fechas. No obstante, las asociaciones de cerámica relacionadas con la primera fase constructiva, la que fue registrada en diferentes sectores del sitio (Silverman 1994b; Orefici 1998, 2012; Bachir Bacha 2007), se caracterizan por la recurrencia de variables relacionadas tanto con el estilo Topará de las fases Jahuay 3 y Chongos (véase Cahuachi Stylus Decorated: Strong 1957, Silverman 1994b; 
en Chincha: Tantaléan et al. 2015, 2018), como Paracas Cavernas y Ocucaje 10. Muchos de estos rasgos se mantienen incluso en las fases posteriores de construcción y uso de las edificaciones ceremoniales (Orefici 1998).

Muy recientemente, Nigra (2017) propuso una secuencia diferente para el valle de Chincha a partir de las estratigrafías comparadas de las Huacas Soto, El Mono y Cerro del Gentil: "Paracas Temprano" en Chincha estaría representado por un período proto-Cavernas, caracerizado por la presencia de alfares marrones con el pulido fino, las variantes más antiguas de las técnicas poscocción y los motivos inicisos reminiscentes de estilos artísticos Chavinoides... "Paracas Medio" en Chincha sería un período paralelo a Cavernas, marcado por el florecimiento de alfares poscocción, tipificados como estilo "Pinta". "Paracas Tardío" en Chincha parece contemporáneo con los cementerios Necropolis y se defininiría por la presencia de alfares Jahuay 3/Chongos» (Nigra 2017:30; tradución de K.M.). Nigra (2017) precisa asimismo que la cerámica de su fase Paracas Medio es comparable con Ocucaje 5-8. Por ende, no se entiende las razones de la comparación con el material Paracas Cavernas. Como se puede apreciar en las publicaciones de cuadernos de Tello (2009; Tello y Mejía Xesspe 1979), de León (2013), de Medina (2013) y de Kolomanski (ver abajo), la cerámica decorada poscocción es poco recurrente en los contextos Cavernas, a diferencia de las vasijas monócromas anaranjados, Topará o emparentadas con este estilo. Por otro lado, tanto la cerámica como los textiles de la cima de Wari Kayan en Paracas, excavada por Tello, fueron asignados de manera coincidente por diferentes investigadores (Dwyer y Dwyer 1975, Dwyer 1979), a las fases 8-10 del Horizonte Temprano. Finalmente, como se discute a continuación no hay evidencias de un cambio cultural brusco entre Paracas Cavernas y Paracas Necrópolis, como Tello ha querido insinuar. Por lo contrario, hay plena continuidad de usos de áreas residenciales y funerarias desde el Horizonte Temprano 7/8 hasta el Período Intermedio Temprano 2. La transición entre el Horizonte Temprano 10 y el Período Intermedio Temprano 1, se vislumbra en el remplazo de una diversidad de estilos alfareros, en la cual resalta la diferencia entre la cerámica Paracas, multicolor poscocción o negativa y esencialmente monocroma con eventual decoración bruñida, la Topará, por la hegemonía de un solo estilo en los ajuares funararios, Topará de las fases Chongos y Campana (véase este volumen).

Los aportes que acabamos de presentar invitan a reconsiderar la definición de la cultura Paracas. Según Julio C. Tello (1959, 1960, 1967; Tello y Mejía Xesspe 1979) Paracas representaba una estadía de desarrollo intermedio entre Chavín, como la cultura matriz centroandina, y el desarrollo de la cultura regional Nasca. Las investigaciones de John H. Rowe y de sus colaboradores (Menzel, Rowe y Dawson 1964) no lo han contradicho en este sentido (Burger 1993). No obstante, las investigaciones posteriores pusieron en evidencia que varios siglos y procesos de notable complejidad separan la época Chavín de Paracas Cavernas. Salvo las técnicas de incisión y algunos arcaísmos, por ejemplo, en los relieves de Callango (Massey 1983, 1991a; Bachir Bacha y Llanos 2011, 2015; García 2010), poco o nada sobrevive de la época en la que relaciones estrechas unían a la costa sur con el mundo Chavín. En Paracas Tardío aparecen, en cambio, numerosos diseños figurativos que caracterizan al estilo Nasca. Ello ocurre tanto en la cerámica como en los textiles producidos en los valles de Ica, Palpa y Nazca. No obstante, estos motivos se realizan en técnicas heredadas de las épocas anteriores: la decoración estructural en el caso de los textiles, y la pintura poscocción en campos separados por incisiones, en el caso de la cerámica decorada. Difieren por lo tanto de las técnicas empleadas posteriormente en el estilo Nasca. A partir de la fase 7, en los valles al Norte de la Península de Paracas se gesta un cambio importante en materia de la producción de cerámica: nace el estilo Topará. Wallace (1963) denomina «estilo Patos» a sus primeras expresiones. Lanning (1960: 397) y Wallace $(1985,1986)$ coincidieron en seńalar al valle de Cańete como el lugar de origen.

Cabe poner énfasis en el hecho de que el nuevo estilo es la expresión de una novedosa tradición tecnológica, que difiere en todos los aspectos de la que imperaba anteriormente, y seguirá aún en uso, la cerámica paracas. La cerámica topará se caracteriza por una cuidadosa preparación de pastas 
de textura fina, la que permite reducir sensiblemente el grosor de las paredes, y por una cocción bien controlada en ambiente oxidante o reductor, bien controlado. En algunos casos, cambios de coloración hacia las tonalidades violáceas sugieren el uso de temperaturas mayores a $1000^{\circ} \mathrm{C}$. Se usa engobes blancos, anaranjados, a veces rojos. La decoración se limita a diseños incisos, bruñidos geométricos, excepcionalmente figurativos y el uso esporádico de la pintura roja sobre el fondo crema, particularmente en el borde (a partir de Jahuay 2 (Wallace sf., Silverman 1997; 2009). Topará difiere de Paracas también en el repertorio de formas en el que predominan cuencos y botellas.

La frontera entre ambas zonas, la que se forma aparentemente a partir de las fases 8 y 9 del Horizonte Temprano, y se mantiene hasta bien avanzado el Período Intermedio Temprano (como frontera norte del estilo Nasca Temprano, fases 3, 4: Silverman 2002b, Silverman y Proulx 2002: 28-29), corta en dos la Península de Paracas, atravesándola de Este a Oeste. En los tiempos de la difusión del estilo Topará, los sitios frente a la bahía de Paracas, con Cerro Colorado y Arena BlancaCabezas Largas, se relacionaban culturalmente con el valle de Pisco. Los sitios en el litoral de la Bahía de Independencia, verbigracia Carhua, mantuvieron vínculos con el valle de Ica. ¿Existen dos culturas independientes, la Paracas y la Topará o se trata de dos expresiones estilísticas de la misma cultura regional? Ambas posiciones están representadas en la literatura. Sawyer (1966:89), Lumbreras (1969), Canziani (1992, 2012), Hill (et al. 2012), Tantaléan (et al. 2015) y Nigra (2017), defienden la segunda alternativa. Wallace $(1985,1986)$, Massey (1983, 1986, 1991a, b), Peters (1989-88; 2010, sf 1, sf 2) y Silverman (1991, 1994a, b, 1997, 2009), optan por la primera. Los partidarios de la segunda opción defienden la tradición académica fundada por Julio C. Tello. Su hipótesis se sustenta en los hallazgos de objetos en ambos estilos en un solo contexto, frecuentes en particular en la península de Paracas (Tello y Mejía Xesspe 1979; Silverman 2002a; Peters 2010, 2012a, b) y en el valle de Ica (Sawyer 1961, 1966; Massey 1986, 1991a). Consideran asimismo crucial el hecho de que ambas áreas, respectivamente al Norte y al Sur de la Peninsula de Paracas, han conocido un común desarrollo en la época Chavín durante la primera mitad del primer milenio a.C.

A favor de que se trata de dos culturas independientes existen otros argumentos de mayor peso a criterio de los autores. En primera instancia, la introducción del estilo Topará significó una ruptura completa con la larga tradición alfarera local, contribuyó a su ocaso y condicionó el nacimiento del estilo Nasca. Resulta claro que la identidad tecnológica (Lechtman 1977; Hegmon 1998; Dobres 2000) que condiciona la cadena operativa de la producción de cerámica en estilo Topará, tiene características muy particulares e incompatibles con los procedimientos y principios rectores, que guían las actuaciones productivas de los alfareros paracas. La arquitectura en cuyo contexto aparece la cerámica Topará, posee características bien definidas que difieren de las que se observan en el caso de las estructuras paracas, tanto en el diseño como en las técnicas constructivas. Ultimamente se ha demostrado (Nigra 2017; Hill et al. 2012) que imponentes conjuntos de patios amurallados sobre plataformas ascendentes, alíneadas de Este a Oeste, los que se encuentran solo en el valle bajo de Chincha (Canziani 1992; Canziani 2012: 158-170), fueron construidos antes de que se difunda la cerámica Topará de las fases Jahuay y Chongos, y en los niveles de uso se registra el estilo Pinta, que guarda ciertas afinidades con el Ocucaje 5-7. Se trata además de arquitectura diferente en todos los aspectos de la que fue registrada en Pisco (Peters 1986, 1989-88, 1997; Silverman 1997), en Paracas (Tello y Mejía Xesspe 1979; Engel 1966) y en Ica (Massey 1992), en relación con la cerámica Topará. En el caso de arquitectura topará, se trata de extensos complejos amurallados de traza ortogonal, como Chongos, y de asentamientos aglutinados con unidadades domésticas de planta rectangular, alineados sobre terrazas, como los dos sitios que albergaban en sus respectivos centros las famosas áreas funerarias Paracas-Necrópolis, a saber Wari Kayán-Cerro Colorado y Cabezas Largas-Arena Blanca (Tello y Mejía Xesspe 1979) Cabe resaltar que la arquitectura pública y residencial Topará difiere también sustancialmente en formas y técnicas de la que fue registrada en relación con la cerámica en el estilo Ocucaje 7/8, 9, 10 en Ánimas Altas-Ánimas Baja en el valle de Ica, Hoya de Callanga (Bachir Bacha y Llanos 2015). 
Las evidencias de la difusión de los estilos Paracas Cavernas y Topará hacia los valles de la Costa Central brindan argumentos adicionales a favor de la hipótesis, en cuyo tenor, cada uno de dichos estilos se habría desarrollado de manera independiente y en un contexto cultural diferente, respectivamente al Sur y al Norte de la Península de Paracas. Las importaciones o imitaciones del estilo Ocucaje Tardío (Paracas Cavernas, Horizonte Temprano 9) fueron registradas en Ancón (Tabío 1965: 78-70, lam.1-3) y la quebrada del río Huaycoloro-Huachipa (Silva y García 1997: 207-213, figs.13-15; Palacios 1999: 5; Silverman 2009), en la cuenca del Rimac. La presencia de la cerámica Cochachongos, originaria del valle del Mantaro, tanto en el Cerro Wari Kayán de Paracas, como en la quebrada de Orcón-Pacaybamba, valle de Chancay, en el período Cerro Polvareda (Goldhausen 2013: 332, seite 21), es una evidencia contundente de la movilidad humana y, asimismo, de la intensidad de las interrelaciones regionales costa-sierra en la época inmediatamente posterior al ocaso de Chavín. Los contactos de la Costa Central con el Sur parecen intensificarse aún más en las fases posteriores, pero sin que se registre la presencia de imitaciones o importaciones del estilo Paracas Tardío. En cambio, los hallazgos de cerámica en estilo Topará son frecuentes. Por ejemplo, cuencos en estilo Topará forman parte de los ajuares funerarios en Tablada de Lurín (Carrillo 2009; Makowski et al. 2012). Los préstamos Topará de las fases Chongos y Campana, y en menor grado Nasca Temprano, se perciben en la cerámica hallada en Villa el Salvador (Delgado 2007) y también en Huachipa (Palacios 1988, sf.; Silverman 2009).

A la luz de las evidencias que acabamos de discutir, la secuencia cultural registrada en la costa centro-sur del Perú durante el primer milenio cal. a.C., carece de continuidad. En la primera mitad de este milenio la plena integración de esta zona con el universo Chavín es evidente. Las relaciones no se limitan, sin embargo, al famoso templo en las orillas del Mosna, sino también atañen a la Costa Norte. Este período está representado en la Peninsula de Paracas (Engel 1966; García y Pinilla 1995; Tellenbach 1998; Dulanto 2015), pero no ha dejado evidencias en los sitios de la bahía del mismo nombre excavados por Tello. Por esta razón, y dado que la totalidad, o en todo caso, la mayoría de los recipientes cerámicos hallados, debieron haber sido producidos fuera de la península, el uso del nombre «estilo y cultura Paracas», carece de sustento satisfactorio.

El término no resulta tampoco cómodo para definir la situación cultural de la costa centrosur en la segunda mitad del primer milenio a.C., tal como esta se presenta desde la perspectiva actual. Las relaciones con el Norte se interrumpieron en esta época, y en cambio, se estrecharon los contactos con la sierra vecina. Estos contactos han repercutido, entre otros, en el aumento vertiginoso de la cantidad de fibra de camélido, hilada y eventualmente teñida (Conklin 1971, 1978). Se intensificaron asimismo las importaciones de obsidiana (León 2007; Young 2018; Burger 2013). La distribución espacial de los estilos de cerámica sugiere que dos cuencas consiguieron sucesivamente en esta época una posición protagónica como centros religiosos y políticos de mayor prestigio: el valle bajo de Chincha y la cuenca de Callango (Ica), con el sitio de las Ánimas. En el primero de ellos se se usaba y se producía la cerámica Pinta, comparable con el Ocucaje 5-7 (Nigra 2017; Tantaléan et al. 2015, 2018), mientras que en el segundo, la cerámica Ocucaje 8, 9, y 10. El efecto de Vries, conocido también como Plateau Halstatt, impide precisar la fecha del inicio de la arquitectura monumental en Chincha, la que se sitúa probablemente en el transcurso del siglo VI a.C. Tantaléan (et al. 2015) y Nigra (2017: 165-167), sugieren que los edificios de este tipo dejaron de construirse antes de 200 a.C. En cambio, para las Ânimas, las fechas TLC de Massey (1990: 146-148), coincidentes en parte con el Paracas Tardío (Ocucaje 8) de Palpa (Unkel 2006: 71; Reindel e Isla 2006: 272), sugieren el período de construcción y uso entre 380 y 100 a.C. (Bachir Bacha y Llanos 2015: 172), si bien Bachir Bacha (2018: 194) propone recientemente 400 a.C. a 50/100 d.C para el sitio y 250 a.C a 50 d.C. para el Edificio de los Frisos.

No obstante, está por demostrarse donde estaban situados los principales talleres de producción alfarera de la cerámica Topará, y precisar la relación cronológica con Pinta de Chincha y Ocucaje de Ica. Por lo pronto, los fechados provenientes de Chincha (Nigra 2017) y de Paracas (León 
2007, 2013) coinciden en señalar el siglo III a.C. como la fecha probable de la formación del estilo Topará. Tal parece que en la fase Nasca Inicial (Ocucaje 10, Nasca 1,2; 120 a.C.-90 d.C, según Unkel 2006: 71 y Reindel e Isla 2006: 272), solo en dos cuencas en la costa centro-sur se construía arquitectura ceremonial de carácter monumental y se producía la cerámica fina de prestigio, en el valle de Pisco (Peters 2015) y en el valle de Nazca (Orefici 2012).

La frontera entre las áreas de interacción dividió en dos, por varios siglos, a la peninsula de Paracas (Silverman 1991, 1997, 2009; Peters 1997; Makowski 2000, 2001, 2004, 2010). Por esta razón, tanto en el valle de Pisco, como en la península de Paracas, se encuentran objetos en diferentes estilos y subestilos. Si los estilos de textiles con decoración bordada (Paul 1982, 1986) fueron producidos por la misma población que usaba cerámica en estilo Topará, como sugieren las asociaciones sistemáticas en los contextos funerarios Paracas Necrópólis (Tello 1959, 2012; Tello y Mejía Xesspe 1979), habría que asumir que el diálogo entre las dos tradiciones iconográficas, la Paracas Tardío (Ocucaje) y la Topará, fue decisivo para la formación del estilo Nasca. A fin del Horizonte Tardío (Ocucaje 10) y al inicio del Período Intermedio Temprano (Nasca 1), la iconografía Nasca se consolida, primero en la producción textil, y luego es imitada por los alfareros, gracias a las nuevas tecnologías de cocción y preparación de pinturas y engobes que se gestan gracias al aporte Topará. Poca duda cabe de que la consolidación del estilo alfarero Nasca (Nasca 2,3), se da en detrimento de Topará y en el contexto del auge del nuevo centro ceremonial de Cahuachi en el valle de Nazca.

\section{La colección de cerámica «Paracas Cavernas» de las excavaciones de Julio C. Tello en el Cerro Colorado (bahía de Paracas)}

Las conclusiones a las que hemos llegado en los acápites anteriores coinciden plenamente con los resultados obtenidos por Tomasz Kolomanski en su analisis de vasijas cerámicas enteras, procedentes de excavaciones en las tres terrazas ubicadas en las pendientes y en la cima de Cerro Colorado, que domina la bahía de Paracas ${ }^{3}$. El estudio ha tenido como meta comprobar el grado de diferenciación de este material y contrastar las propuestas de correlación con las cronologías relativas, propuestas en la literatura del tema. A pesar de frecuentes cambios en la numeración del registro en el Museo Nacional de Arqueología, Antropología e Historia del Perú (MNAAHP), y gracias al eficiente apoyo de su personal, hemos logrado identificar de manera fehaciente las vasijas.

El 26 de julio de 1925, Julio C. Tello inició sus investigaciones en la peninsula de Paracas con prospecciones en dos áreas, Cerro Colorado (llamado posteriormente Wari Kayán: Tello y Mejía Xesspe 1979: 98, 99, 298, 305.) y Arena Blanca (Cabeza Larga). Los contextos en Cerro Colorado fueron numerados según su ubicación en tres terrazas (I-III) de la cima. Las excavaciones siguieron a las prospecciones durante tres temporadas, desde agosto de 1925 hasta octubre de 1930. La cerámica proveniente de estos trabajos se conserva hasta el presente en el MNAAHP, en Pueblo Libre, Lima. Luego de un arduo trabajo de confrontación de los números de inventario con los diarios de campo, conservados en el Instituto Riva Agüero de la Ponitificia Universidad Católica del Perú, y con los apuntes de Toribio Mejía Xesspe y de Antonio Hurtado, Tomasz Kolomanski, ha logrado comprobar la procedencia de 67 vasijas encontradas en los contextos funerarios de Cerro Colorado, que Tello y Mejía Xesspe (Tello 1959; Tello y Mejía Xesspe 1979) asignaron a su fase Cavernas. Se ha intentado también identificar con precisión los contextos de cada hallazgo, tarea que tropezó con varios obstáculos. Los números de los contextos funerarios en los originales de los diarios de campo, no siempre coincidían con los que fueron consignados en los informes y en las publicaciones posteriores. Adicionalmente, Tello y Mejía Xesspe no siempre respetaban su propia terminología y usaban de manera alterna los terminos "tumba» y "caverna", sin tomar en cuenta la forma de la matriz del entierro ${ }^{4}$. En varios casos se ha borrado por completo el número original del inventario asignado durante las excavaciones. Debido a los problemas arriba mencionados se ha logrado precisar el contexto del hallazgo de 31 vasijas ( $46 \%$ de la totalidad de la muestra 
proveniente de Cerro Colorado). Los ceramios fueron encontrados en 15 contextos diferentes: 17 vasijas provienen de entierros de cámara (cavernas) y 14 de entierros en fosa. Según las notas de campo, en los entierros de cámara, los recipientes cerámicos se encontraban, tanto dentro de los envoltorios de fardos, como en el espacio adyacente. En cambio, en los entierros de fosa, las vasijas estuvieron depositadas cerca de la base del fardo. Solo excepcionalmente se encontraron ofrendas cerámicas en las partes superiores de la fosa.

\section{Analisis tecnológico y tipológico-formal}

Las 67 vasijas de Cerro Colorado conservadas en los depósitos del MNAAHP corresponden a un número de formas relativamente reducido. Los cuencos son mayoritarios: 42 piezas, es decir $62.6 \%$ de la totalidad de la muestra, seguidos por 11 platos hondos $(16.4 \%), 5$ ollitas sin cuello (7.5\%), 4 botellas con gollete corto $(6 \%)$ y 2 botellas asa-puente (3\%). La muestra comprende también a 1 figullina antropomorfa (1.5\%) y 1 ollita con cuello corto evertido (1.5\%). Todas las vasijas se encuentran en perfecto estado de conservación. Solo en algunos casos, pequeñas roturas de los bordes o desprendimientos en la superficie, permitieron apreciar la presencia de temperantes arenosos de grano medio. En el análisis de la variabilidad hemos tomado en cuenta las características morfológicas, el color y el tamaño de las inclusiones, el color de la pasta, el espesor de las paredes, la forma del borde y del fondo, el color y el acabado de superficie en el interior y en el exterior del recipiente. En cuanto a las técnicas decorativas presentes en el exterior y en el interior, hemos tomado en cuenta la presencia/ausencia de negativo, de diseńos pintados pre y poscocción, y de incisiones en pasta cuero y en pasta seca. Se ha registrado por supuesto también la gama de colores y el repertorio de diseños. El resultado del análisis cluster, a partir de las matrices de presencia/ausencia, nos ha permitido clasificar la totalidad del material en tres grupos, además de un solo caso de vasija claramente importada de la sierra (Gráfico 1).

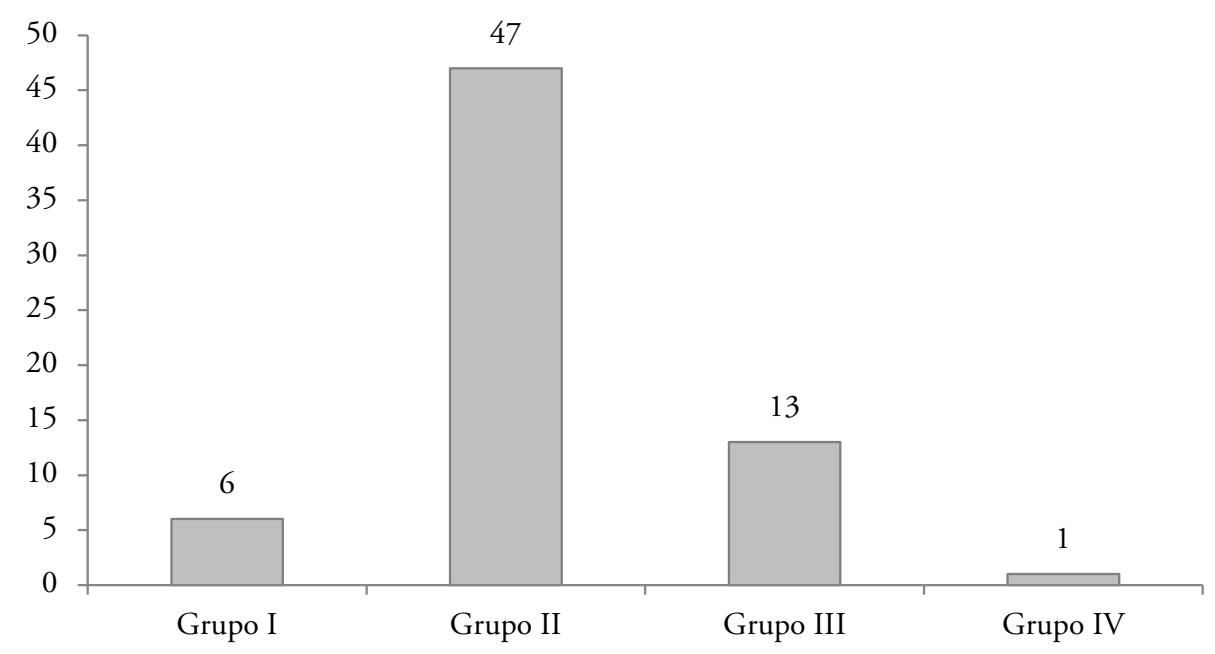

Gráfico 1. Grupo I: cuencos y platos, engobe crema Topará. Grupo II: cuencos, platos, botellas, figurina, engobe marrón o rojo, decoración incisa, negativa, pintura resinosa. Grupo III: cuencos, platos, cántaros, engobe marrón claro, bruñido, ocasionalmente pintura roja. Grupo IV: cuenco rojo sobre crema Cochachongos. 


\section{Grupo I}

El primer grupo comprende solo dos tipos formales, a saber: cuencos y platos hondos.

Cuencos (Figs. 1a y 1b). Las vasijas tienen paredes de 0.5 centímetros de espesor en promedio, labios adelgazados, fondo redondeado. Las paredes adoptan la dirección casi vertical cerca del borde, con una ligera inclinación hacia afuera. La superficie, por lo general pulida, es de color marron claro. Algunos ejemplares tienen una banda roja pintada en la parte interna y externa, y su interior posee engobe de color crema. Se registra también casos de decoración figurativa: estrella, pez o figura fitomorfa.

Platos hondos. A diferencia de los cuencos, los platos hondos del primer grupo se caracterizan por las paredes evertidas que se unen con el fondo redondeado sin carena. El espesor de las paredes es también $s$ de aprox. 0.5 centímetros, pero los labios son adelgazados. La superficie externa, de color marrón claro, es por lo general pulida. Algunos ejemplares están recubiertos de engobe crema en su interior y decorados, al igual que los cuencos, con una banda de color rojo en el borde. En un solo caso, debajo de la banda corre una franja de incisiones verticales corta. (Figs. 1c y 7d).

El grupo I comprende seis cuencos y dos platos (9\% de la muestra).

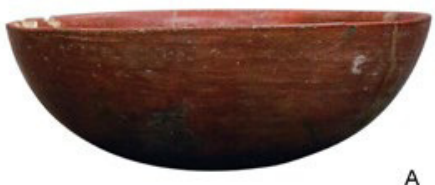

A
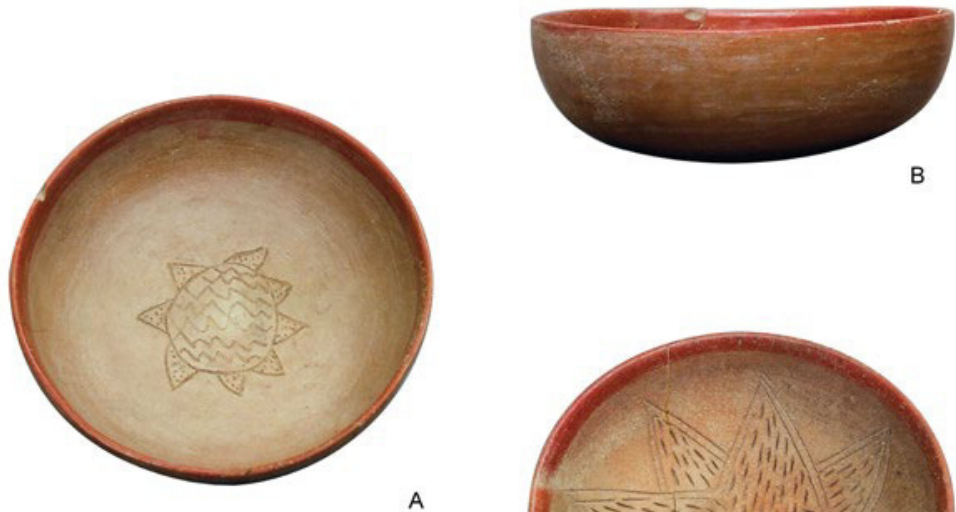

B

A
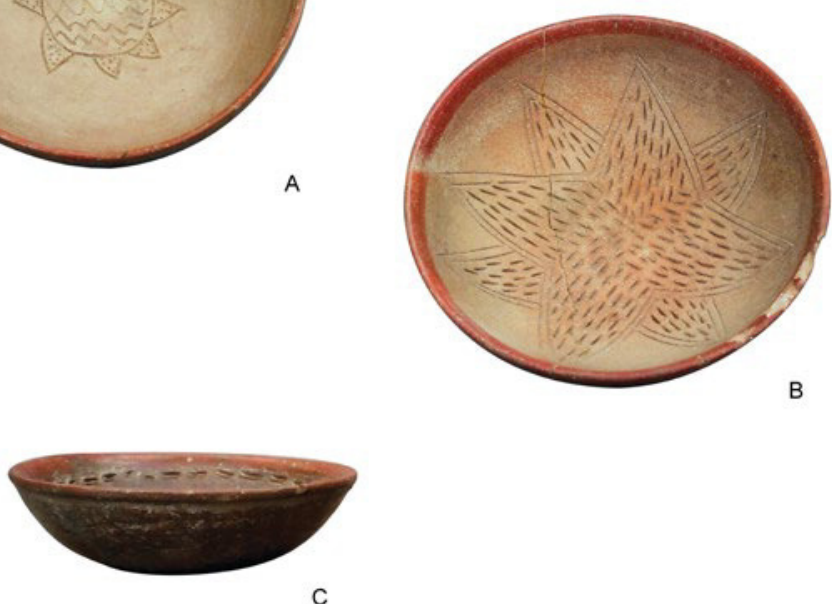

Figura 1. Cerámica del grupo I. A: Esp. C-15769 (12/8182) - $N^{\circ}$ de cat.: 60; B: Esp. C-16094 (12/5104) - No de cat.: 21; C: Esp. C-15970 (12/8234) - $N^{\circ}$ de cat.: 55. 


\section{Grupo II}

El grupo II está integrado por cuatro tipos: tazones, vasos de fondo redondeado que adoptan una forma similar a una pequeńa olla sin cuello, botellas con gollete o con asa-puente. A este grupo pertenece también la única figulina antropomorfa de la colección.

Tazones (Figs. 3a-h). Los tazones adoptan formas parecidas a los platos hondos, pero se diferencian de ellos por la mayor profundidad. Sus paredes son rectas y evertidas. Una carena se forma en la unión con el fondo redondeado creando un aspecto campaniforme. Las paredes más gruesas son un poco más gruesas que los cuencos y platos hondos del grupo anterior dado que oscilan entre 0.5 y 0.6 centímetros. Los labios son adelagazados y redondeados. Las paredes son rectas y evertidas o concavas dando una apariencia campaniforme a la vasija. Las superficies exteriores de las vasijas, de color marrón claro, ocasionalmente naranja, rojo, marrón oscuro, gris o negro, fueron acabadas con pulido. El interior de los tazones fue engobado de color rojo, marrón, u ocasionalmente naranja. Cuando las paredes interiores están acabadas con pulido, sin estar cubiertas de engobe, su color es gris o negro. En contados casos la superficie está decorada con incisiones cortantes y con pintura resinosa poscocción. En un caso una banda bicolor rodea el borde sobre las paredes exteriores y una línea ancha de color amarillo forma un entrelazado en el medio del fondo naranja (Fig. 3f). En otro tazón (Fig. 3e), una banda ancha (3.9 centímetros de ancho) con signos escalonados corre a 0.5 centímetros por debajo del borde. La decoración combina varios colores: blanco, amarillo, rojo, verde, marrón y negro. En el segmento de la pared exterior donde la banda se interrumpe, hay puntos blancos y rojos que forman líneas verticales paralelas. Una decoración relativamente compleja con la misma técnica ocupa la pared interna. Una línea incisa, 0.5 centímetros por debajo del borde y otra en el límite con el fondo delimitan una zona cubierta con pintura negra. El fondo a su vez esta dividido en cuatro partes iguales por líneas incisas pintadas de manera alterna con los colores rojo y amarillo. Solo en un caso se ha registrado decoración figurativa compleja junto a la geométrica. Se trata de la figura sobrenatural conocida en la literatura del tema como Occulate Being, la cual está incisa y pintada en el interior del tazón. El exterior en cambio tiene un diseño entrelazado (Fig. 3h). En un caso también (Fig. 3g), las paredes están decoradas con alíneamientos de puntos de color naranja logrados en la técnica de negativo.

Copas de fondo redondeado. Estas pequeñas vasijas, cuya forma se asemeja a la de mates u ollas sin cuello, poseen paredes relativamente finas entre, 0.3 y 0.5 centímetros de grosor. Sus bordes son ligeramente redondeados y sus fondos redondos. Las paredes exteriores de las vasijas, de color gris o naranja, fueron acabadas con pulido. La decoración es incisa y pintada poscocción en multiples colores: amarillo, verde, rojo y negro. Los diseños son geométricos. Una banda con el signo escalonado corre debajo del borde. En un caso el campo entre los diseńos geométricos incisos está rellenado por triangulos punteados de color blanco (Fig. 2e).

Botellas con gollete central (Fig. 2b-d). Sus paredes son de un grosor promedio de 0.5 centímetros. El cuello corto posee borde continuo evertido con labio ligeremente engrosado. La superficie, de color gris o marrón claro, está acabada por pulido (Fig. 2c-d). Los fondos, por lo general planos, pueden ser también ligeramente redondeados. Solo en un caso se ha registrado decoración con incisiones que conforman bandas rellenas de diseños geométricos (Fig. 2b). Los campos al interior de las líneas incisas están pintados con pinturas resinosas post cocción de color blanco, rojo, amarillo y verde. La parte sin decoración es negra.

Botellas asa-puente. Como en el caso anterior, hay botellas de color marrón sin decoración de superficie (Figs. 2f y 7b) y las hay también con diseños incisos y pintados con pintura resinosa poscocción. En ambos casos la superficie es pulida. En la muestra analizada hay dos ejemplares, uno por cada tipo de decoración mencionado. En la botella decorada con pintura resinosa poscocción, un diseño de ave está representado tanto en la parte superior como la lateral del puente. Los colores son variados: amarillo, rojo y negro. El cuerpo de las botellas es compuesto, lenticular con carena en la parte medial y con el fondo plano. Los golletes tienen parte inferior troncocónica y la superior, tubular. Los labios tienen un bisel externo. 

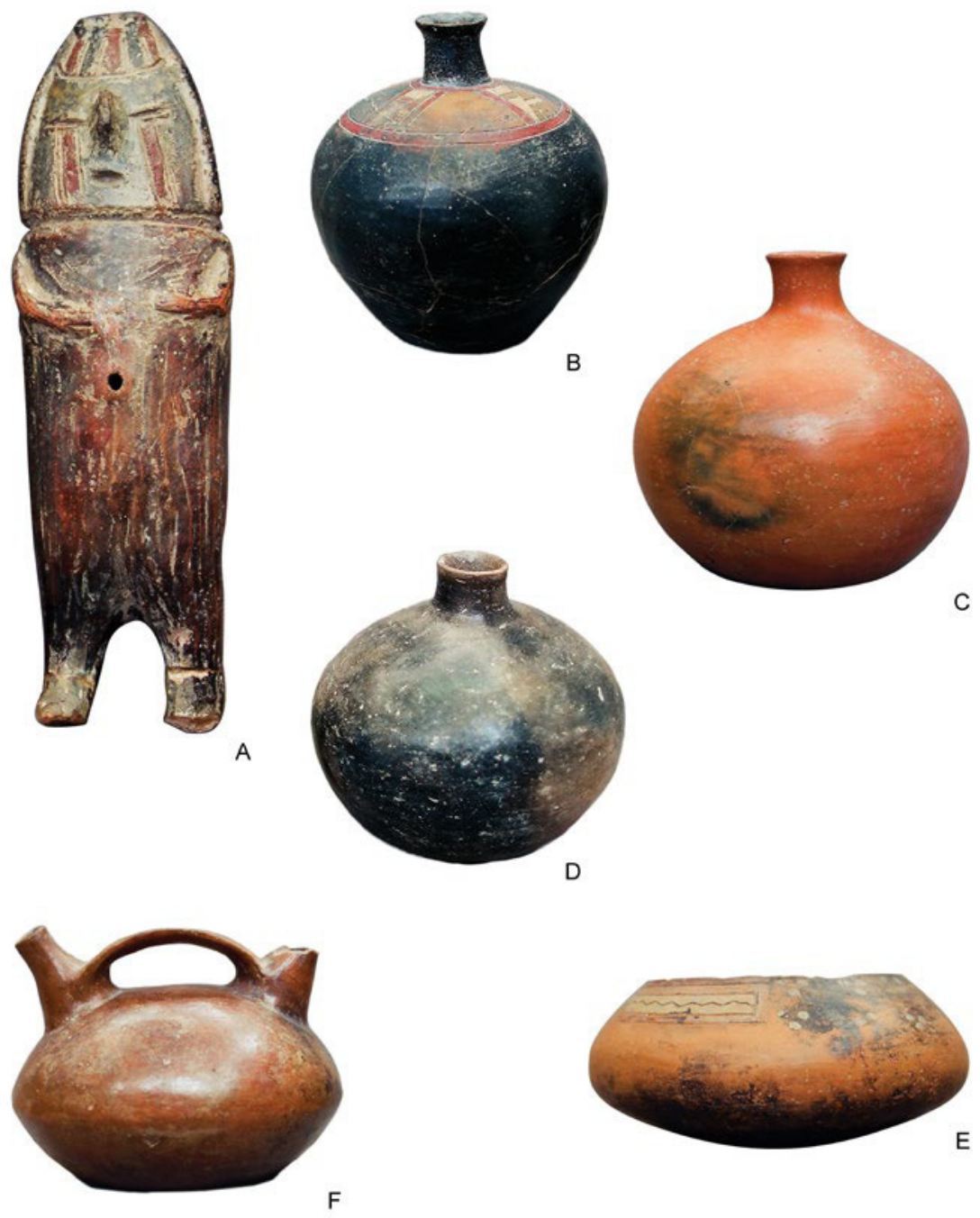

Figura 2. Cerámica del grupo II. A: figurina antropomorfa identificada como elemento del contenido de la caverna $V$ - Esp. C-12540 (13/52) - $N^{\circ}$ de cat.: 14; B: Esp. C-15899 (12/8357) - $N^{\circ}$ de cat.: 54; C: Esp. C-16235 (12/6560) - No de cat.: 3; D: Esp. C-12/5128 - No de cat.: 22; E: Esp. C-15865 (12/8258) - No de cat.: 33; F: Esp. C-16217 (12/5279) $-N^{\circ}$ de cat.: 30 .

Figurina (Figs. 2a y 7a). La única figulina en nuestra colección representa una figura humana sin rasgos de sexo definidos ni tampoco detalles del atuendo, salvo para el tocado. Este último se compone de una mantilla que cubre parte de la frente y cae a ambos lados de la cara. El personaje está parado, con las manos flexionadas y apoyadas sobre el vientre, debajo del pecho. El dorso carece de detalles anatómicos o de vestido. La figurina, hueca al interior, fue hecha de dos mitades posteriormente pegadas. Un pequeño orificio circular de 0.2 centímetros de diámetro está perforado a la altura del vientre, posiblemente para facilitar la cocción. Los detalles son incisos y modelados. La cabeza está separada del cuerpo por una profunda incisión cortante en pasta cuero. De la misma manera están marcados los ojos, la boca, los dedos de las manos y el pliege entre los pies y los tobillos. La nariz y las manos están modeladas. Solo la cara del personaje y la parte frontal del tocado fueron decoradas con pintura resinosa aplicada entre líneas finas incisas. Bandas verticales en tres 
colores, verde, rojo y negro, conforman la decoración de la mantilla y también están pintadas como lagrimales. La superficie de la estatuilla es marrón con manchas oscuras de cocción mal controlada y fue acabada con un pulido poco cuidadoso que se acerca al bruñido. Una de los pies fue parcialmente roto en la antigüedad.

El grupo II que acabamos de caracterizar es decidamente mayoritario en la muestra analizada y comprende 47 vasijas: 37 tazones y cuencos, 4 botellas con gollete central corto, dos botellas asapuente, tres copas de fondo redondeado, así como una estatuilla antropomorfa. Se trata por ende de $70 \%$ de la totalidad de la muestra analizada.

\section{Grupo III}

El grupo III está conformado esencialmente por platos hondos. Otras formas, como tazones, cuencos, copas y cántaros están representadas por un solo ejemplar cada una. Todas las formas se distinguen de otros grupos por tener paredes finas, de 0.3 centímetros en promedio.

Platos hondos (Fig. 4a-c). Los recipientes de este tipo, bien cocidos en ambiente oxidante, tienen paredes ligeramente convexas. Los labios son adelgazados y redondeados. Los fondos son planos o ligeramente redondeados. Las superficies internas están engobadas con arcillas de color naranja, marrón claro o marrón, y luego acabadas con pulido fino. En un caso (Fig. 4a) el plato hondo fue engobado y pulido tanto en el exterior como en el interior. En dos recipientes la forma del fondo está resaltada por una línea incisa (Fig. 4b-c).

Tazón (Fig. 4d). Este cuenco de gran tamaño tiene paredes finas de forma convexa que se unen sin carena con el fondo redondeado. El labio está adelgazado. La superficie está decorada con bandas verticales rojas, tanto en el interior como en el exterior. En el exterior las bandas llegan a la altura del fondo (3.7 centímetros de largo) mientras que en el interior solo delimitan el borde ( 0.3 centímetros de largo). La superficie, tanto interna como externa, fue acabada con pulido fino. El tazón hace recordar la cerámica San Pablo de Pozuelo (Lanning 1960: 420-423).

Cuenco (Fig. 4f). El cuenco difiere del tazón anteriormente descrito por el tamaño. Tiene paredes finas, fondo redondeado y labio adelgazado. Como en el caso anterior, la decoración es negativa y se compone de bandas rosadas que contrastan con el color marrón claro de la superficie acabada con pulido fino.

Cántaro (Fig. 4e). Esta pequeña vasija tiene cuerpo globular y cuello mediano de paredes rectas. El labio es adelgazado. La superficie, de color marrón claro, fue acabada con pulido y no posee decoración alguna.

Copa con reborde (Fig. 4g). Esta forma muy particular se distingue de las demás tanto por el cuerpo globular con ligara carena y fondo redondo, como por el pronunciado borde evertido en diagonal. El labio es adelgazado. La superficie es de color marrón rojizo con manchas marrón oscuro. La decoración fue hecha en técnica de negativo: bandas verticales paralelas rojizas ocupan toda la superficie del reborde y un segmento del cuerpo, tanto en el exterior como en el interior, contrastando con el color de la superficie.

Las 13 vasijas (nueve platos hondos, un cuenco, un tazón, un cántaro, y una copa), conforman el $20 \%$ de toda la muestra estudiada.

A parte de las vasijas que acabamos clasificar en tres grupos, Tello (Tello y Mejía Xesspe 1979) encontró en Cerro Colorado un cuenco que difiere de todos los demás ceramios en cuanto a las características de forma y acabado (Grupo IV, Figs. 4h y 7c), tratándose de una pieza importada desde la sierra (estilo Cochachongos). Se trata de un cuenco cerrado con labio adelgazado y redondeado. A partir de la quinta parte de altura las paredes cambian de orientación y empiezan a cerrarse. El fondo es redondo. Toda la superficie es de color crema y fue pulida, previa aplicación de la decoración pintada de color rojo. La decoración se compone de dos zigzags cursivos entre campos de color cuadrados, y conforma una franja delimitada en su parte inferior por una gruesa línea continua. 

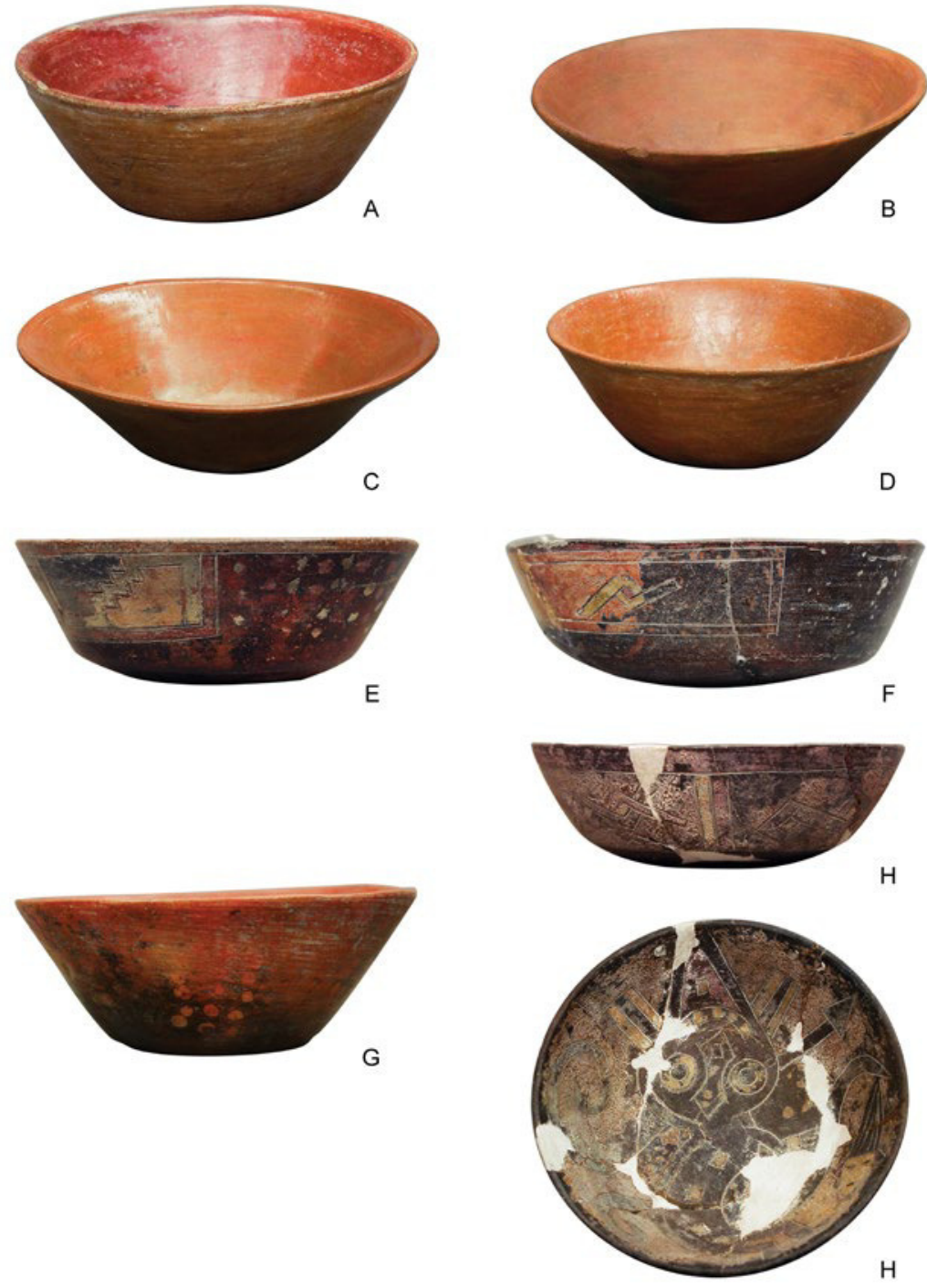

Figura 3. Cerámica del grupo II. A: Esp. C-15944- $N^{\circ}$ de cat.: 8; B: Esp. C-15952 (12/8240) - No de cat.: 49; C: Esp. C-15946 - No de cat.: 11; D: Esp. C-15933 (12/8236) - $N^{\circ}$ de cat.: 43; E: Esp. C-15866 (13/341) - $N^{\circ}$ de cat.: 4; F: Esp. C-15867 (12/5291) - $N^{\circ}$ de cat.: 2; G: Esp. C-15956 (12/8144) - $N^{\circ}$ de cat.: 46; H: Esp. C-15882 (12/8227) - No de cat.: 57.

\section{Análisis comporativo de estilos y de la probable procedencia de las vasijas de Cerro Colorado}

Varias premisas hacen creer que las vasijas encontradas por Tello no fueron producidas localmente en la peninsula de Paracas. Entre estas premisas hay que mencionar:

1. El bajo número de hallazgos de ofrendas cerámicas en comparación con la gran cantidad de individuos sepultados, tanto en la fase Cavernas como posteriormente en la fase Necrópolis.

2. La subrepresentación de botellas y cántaros en la muestra, en comparación con las formas predominantes, livianas y de tamaño reducido como cuencos, tazones y copas.

3. La diversidad de estilos y técnicas. 

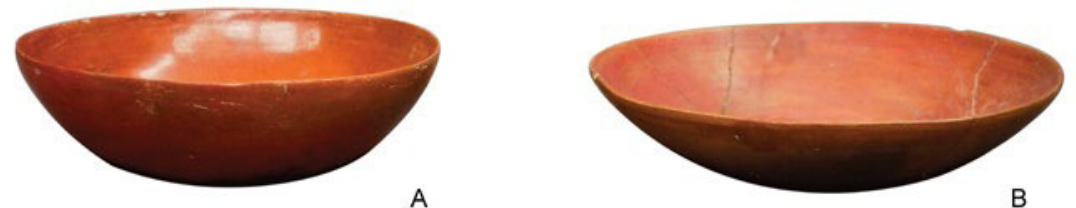

A

B
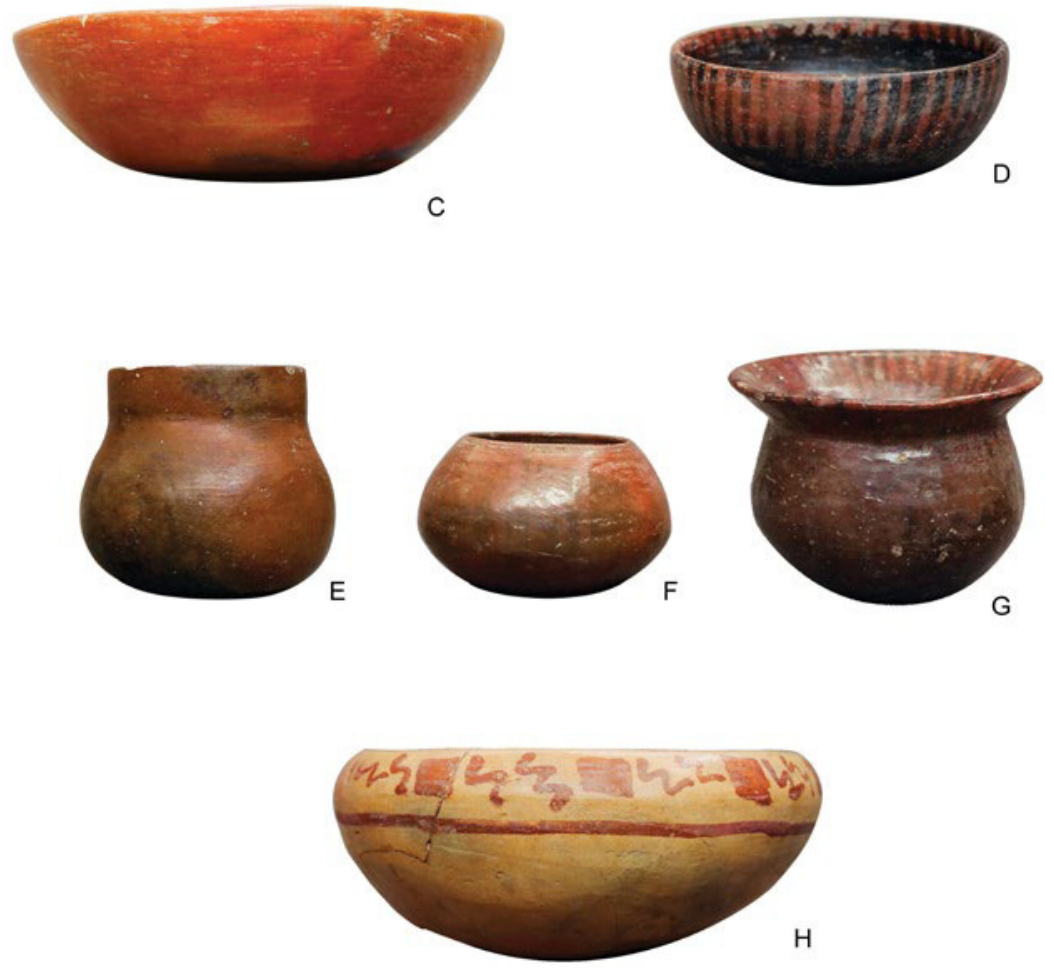

Figura 4. Cerámica de los grupos III y IV. A: Esp. C-16091 (12/6291) - No de cat.: 15; B: Esp. C-16110 (12/6341) - $N^{\circ}$ de cat.: 17; C: Esp. C-15985 (12/6576) - No de cat.: 31; D: Esp. C-15763; E: 12/8226 - No de cat.: 10; F: Esp. C-15838 (12/5205) - No de cat.: 27; G: Esp. C-15861 (12/8147) - No de cat.: 32; H: Esp. C-16114 (12/5256) - No de cat.: 28.

4. Casos claros de importación como la vasija del valle del Mantaro.

5. Falta de evidencias de que haya habido áreas de producción de cerámica en alguno de los dos asentamientos de la bahía de Paracas.

6. Dificultad de acceso al agua y a las fuentes de arcilla. Si bien habrían existido puquios en la antigüedad en la bahía de Paracas, su caudal debió ser restringido, y las fuentes de arcilla y de combustible estuvieron ubicadas a distancia considerable, probablemente en el valle de Pisco.

7. Los estudios sobre los ajuares funerarios de los entierros de la fase Necrópolis (Yacovleff y Muelle 1934; Tello y Mejía Xesspe 1979; Paul 1980, 1990; Peters 2010; Medina 2013) demostraron que no solo los artefactos de obsidiana, sino también los textiles, fueron confeccionados a partir de materias primas importadas desde la sierra y por productores que provenían de lugares diferentes, buena parte de ellos distantes de Cerro Colorado. 
Para costrastar la hipótesis que se acaba de exponer, la muestra fue comparada sistemáticamente con materiales cerámicos publicados que proceden de los valles vecinos al norte y al sur de la península de Paracas: Chincha, Cañete, Pisco y la parte alta de la cuenca de Ica. En esta comparación se ha tomado en cuenta la cronología relativa propuesta en la literatura y adoptada por la mayoría de investigadores. Desafortunadamente, los autores no han podido realizar estudios comparativos de pastas, ni con métodos petrográficos convencionales, ni con métodos espectrográficos. Ello se debe a las limitaciones de fondos y al carácter museable de la colección, compuesta de recipientes enteros. Tampoco disponíamos de un muestrario de arcillas. Por lo tanto, la comparación tuvo que limitarse a variables de forma y de acabado de superficie. A pesar de ello, Kolomanski ha obtenido resultados sólidos que tendrían que complementarse en el futuro con estudios ceramológicos avanzados.

Cada uno de los cuatro grupos previamente definidos guarda relación firme con una tradición alfarera concreta y diferente de las demás, siendo a su vez originaria de una zona diferente (Tabla 2). El grupo I de Cerro Colorado guarda indudable parentesco con la cerámica hallada en la cuenca de Cañete, en particular con la que fue clasificada en las fases más tempranas, incluyendo Patos, según la clasificación de Wallace (1963). Este investigador ubicaba en esta fase el origen del estilo Topará (Wallace 1963, 1985, 1986). Lanning (1960) y Wallace $(1985,1986)$ han realizado una comparación del material hallado en el sitio epónimo estratificado de Jahuay, en la quebrada del mismo nombre ubicada entre los valles de Cañete y Topará, con la colección de cerámica procedente del valle de Cañete, en particular del sitio Quebrada. Gracias a ello, se ha obtenido la primera propuesta de secuencia cronológica para el fin del Horizonte Temprano y el inicio del Período Intermedio Temprano, a partir del estudio de tradiciones alfareras que no guardan ninguna relación con los estilos conocidos de Chavín de Huantar. La compleja sobreposición de niveles de ocupación y conchales registrada en la pequeña aldea de pescadores de Jahuay, ha servido para subdividir la secuencia en fases a partir de criterios estratigráficos. Según Silverman (2009; 1991: 379-380, cuadro 9.2.; 1997: fig. 2), quién ha revisado recientemente la argumentación de Wallace (loc.cit.), los fragmentos Jahuay 1 fueron hallados exclusivamente en Jahuay y los de la fase Patos solo en Cañete. En cambio, el material Jahuay 2 y $2 \mathrm{~B}$ se encontró en ambos valles. La expansión del estilo Topará hacia el Sur y hacia el Norte dataría de la fase Jahuay 3. No obstante ello, las vasijas del Grupo I ostentan rasgos anteriores a esta fase e incluso guardan parecido con la cerámica de la fase Patos.

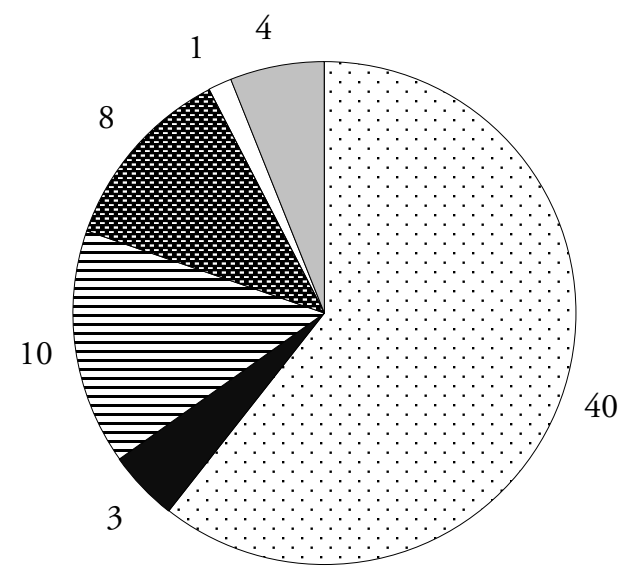

\author{
$\checkmark$ Horizonte Temprano $8-$ \\ Ocucaje del valle alto de Ica \\ Horizonte Temprano 9 - \\ Ocucaje del valle alto de Ica \\ $\boxminus$ Intermedio Temprano 1 - \\ toparoide del valle alto de Ica \\ 固 Fase Chongos - Alto del Molino \\ (valle de Pisco) \\ $\square$ Fase Jahuay 3 - Chongos (valle \\ de Pisco) \\ $\square$ Material no identificado
}

Gráfico 2. Recurrencia porcentual de estilos y subestilos probablemente originarios de los valles circundantes en el material proveniente de las excavaciones de Julio C. Tello en Cerro Colorado. 


\section{Cerámica de Cerro Colorado (grupo II)}
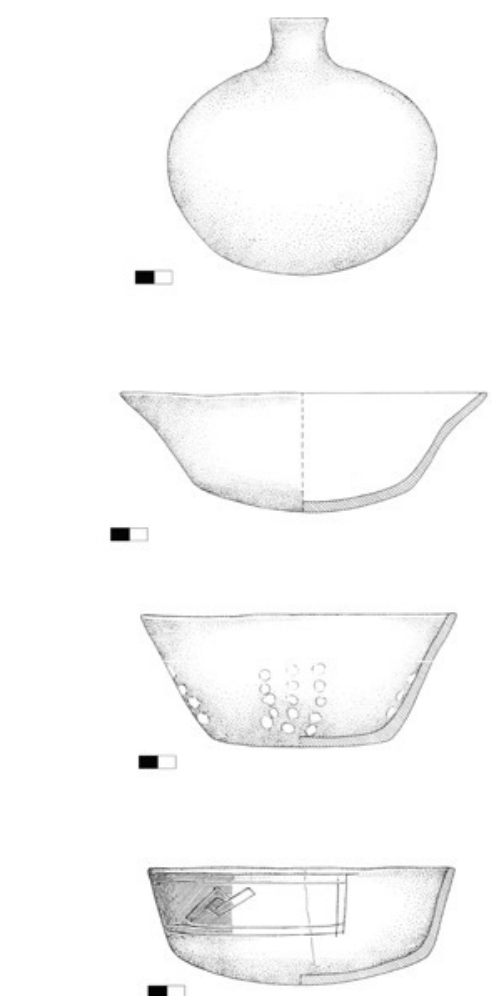

-
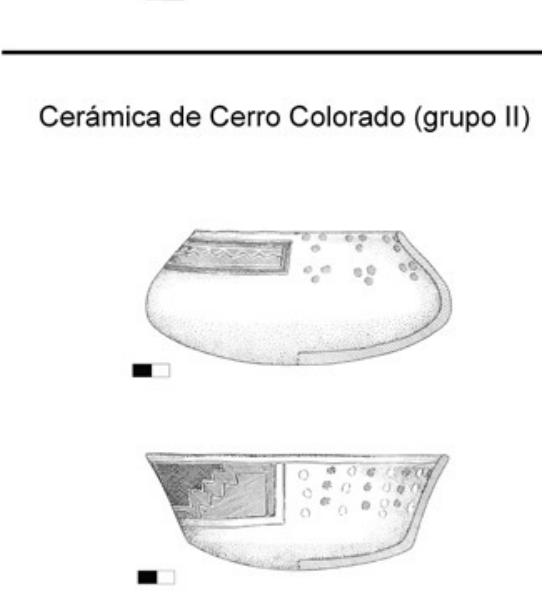

Cerámica del Horizonte Temprano 3 procedente de las excavaciones en la parte alta del valle de Ica

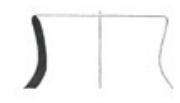

$$
-4^{4 m}
$$
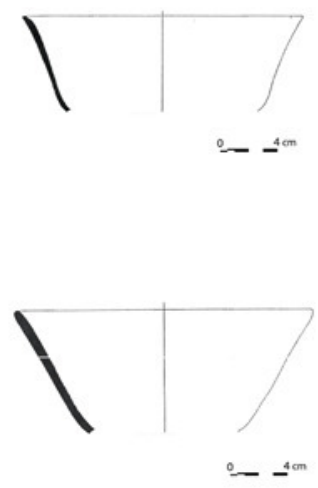

Cerámica del Horizonte Temprano 4 procedente de las excavaciones en la parte alta del valle de Ica

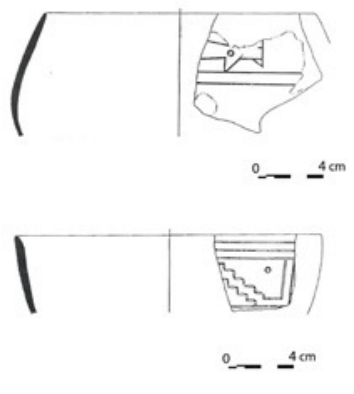

Figura 5. Comparación de cerámica de Cerro Colorado (grupo II) con la cerámica del Horizonte Temprano 3 y Horizonte Temprano 4 procedente de las excavaciones en la parte alta del valle de Ica. 
Las vasijas del grupo II (Gráfico 2), se parecen a la cerámica documentada en la parte superior del valle bajo de Ica, la que fue asignada a las fases 9 y 10 (Menzel, Rowe y Dawson 1964; correspondientes a las fases 3 y 4 del valle de Ica en la cronología de Massey (1983, 1986, 1991a, b). No se encuentran paralelos formales convincentes en el material publicado para algunas de las piezas, pero sus carácterísticas de acabado sugieren la misma procedencia. Este es el caso de tres piezas excepcionales en cuanto a la complejidad de la forma y de la decoración: la estatuilla antropomorfa y dos botellas asa-puente (Fig. 5). Las tres están decoradas con diseńos incisos cuyos campos internos fueron rellenados con pinturas resinosas. No cabe duda de que, a raíz de estos hallazgos, Tello (2012; Tello y Mejía Xesspe 1979) se convenció de que la Peninsula de Paracas y el valle de Ica compartían el mismo estilo, el estilo que Menzel, Rowe y Dawson (1964) llamaron Ocucaje.

La cerámica del grupo III (Gráfico 2) pertenece sin duda al estilo Topará en su fase expansiva (Wallace 1985, 1986) guardando un parentesco muy estrecho con el material encontrado en Chongos y Alto del Molino en el valle de Pisco, y también en el valle alto de Ica, en los sitios asignados a la primera fase del Período Intermedio Temprano. Algunas vasijas presentan características de la fase Jahuay 3. La procedencia precisa es imposible de establecer debido a la sencillez de las formas y el nivel tecnológico, muy alto y uniforme, tanto en la cocción como en el acabado. De manera similar a la producción alfarera de los valles de Cañete, Chincha y Pisco, las vasijas del grupo III de Cerro Colorado fueron hechas de arcilla fina muy bien preparada, logrando paredes muy finas y cocción oxidante controlada en altas temperaturas. La superficie es engobada de naranja, marrón, rojo o crema. El pulido es recurrente. La decoración es escasa. En el caso de los platos hondos del Período Intermedio Temprano I (cinco ejemplares), hemos encontrado características comunes con las piezas registradas tanto en Alto del Molino (valle de Pisco) como en la parte alta del valle de Ica (Fig. 6).

Una sola vasija (grupo IV) parece haber sido importada desde el valle del Mantaro (Tello y Mejía Xesspe 1979; Silverman 1991: 16; García y Pinilla 1995: 64; tabl. XIV) y representa un caso clásico del estilo Cochachongos (Browman 1970, 1977).

En nuestra clasificación en cuatro grupos hemos dado prioridad a variables que se desprenden de una tradición definida de confección, en lugar de mantener a todo precio la subdivisión según rasgos fósiles, que de manera hipotética se cree diagnósticos de una época definida del Horizonte Temprano o del Período Intermedio Tardío. De esta manera, hemos logrado, creemos, nuestro objetivo, a saber, demostrar que la cerámica hallada en contextos funerarios de Cerro Colorado de la fase Paracas Cavernas no pertenece a una sola tradición tecnológica y menos a un estilo, llámese este Paracas Cavernas como la fase, u Ocucaje.

Si se quisiera aplicar los criterios establecidos por Lanning y Wallace para el estilo Topará y Menzel, Rowe y Dawson (1964) a la muestra procedente de Cerro Colorado, la cronología relativa del sitio podría ser definida de la manera siguiente. Los especimenes del grupo I se clasificarían como pertenecientes a las fases 8 (Patos) y 9 del Horizonte Temprano. El grupo II posee características de las fases 9 y 10 del Horizonte Temprano, mientras que el grupo III se asignaría a la fase 10 del Horizonte Temprano (estilo Jahuay 3 de Chongos), así como a la fase 1 del Período Intermedio Temprano.

\section{Conclusiones}

Tanto la revisión de los resultados de las investigaciones recientes, como el análisis del material conservado en el Museo de Arqueología, Antropología e Historia del Perú, el mismo que sirvió a Julio C. Tello para acuñar los términos Paracas Cavernas y Paracas Necrópolis, llevan a conclusiones coincidentes. Los ajuares cerámicos de la fase Paracas Cavernas en la cima de Cerro Colorado, bahía de Paracas, comprenden vasijas de varios estilos contemporáneos, lo que se desprende probablemente de su variada procedencia, respectivamente del valle bajo de Pisco (Jahuay-Topará), del valle alto de Ica (cerámica llana Ocucaje), y del valle bajo de Ica (cerámica pintada poscocción Ocucaje). 


\section{Cerámica de Cerro Colorado (grupo III)}

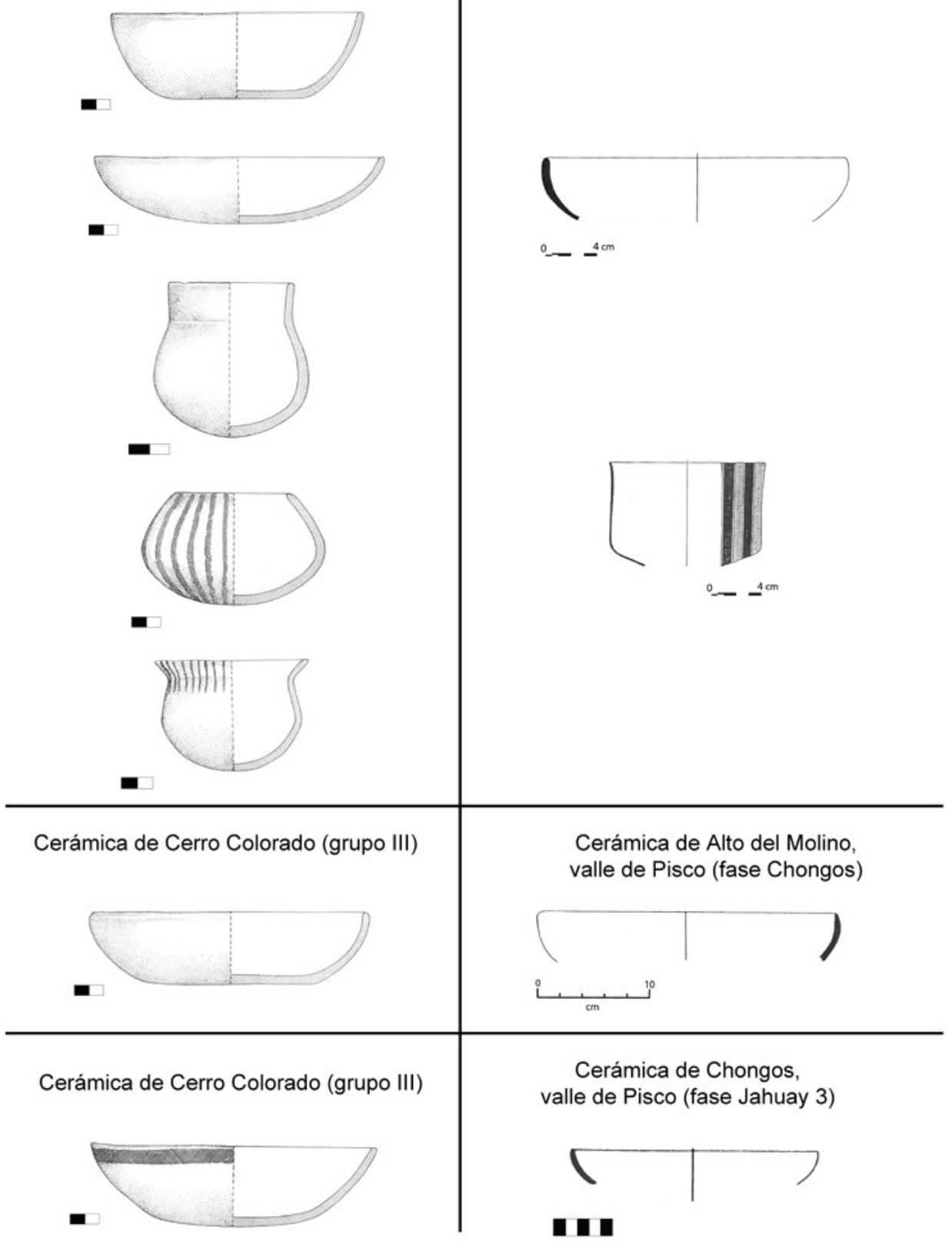

Cerámica del Intermedio Temprano 1 procedente de las excavaciones en la parte alta del valle de Ica

Cerámica de Alto del Molino, valle de Pisco (fase Chongos)

11

Figura 6. Comparación de cerámica de Cerro Colorado (grupo III) con la cerámica del Intermedio Temprano 1 procedente de las excavaciones en la parte alta del valle de Ica, con la cerámica de Alto del Molino (fase Chongos) del valle de Pisco, y con la cerámica de Chongos (fase Jahuay 3) del valle de Pisco. 


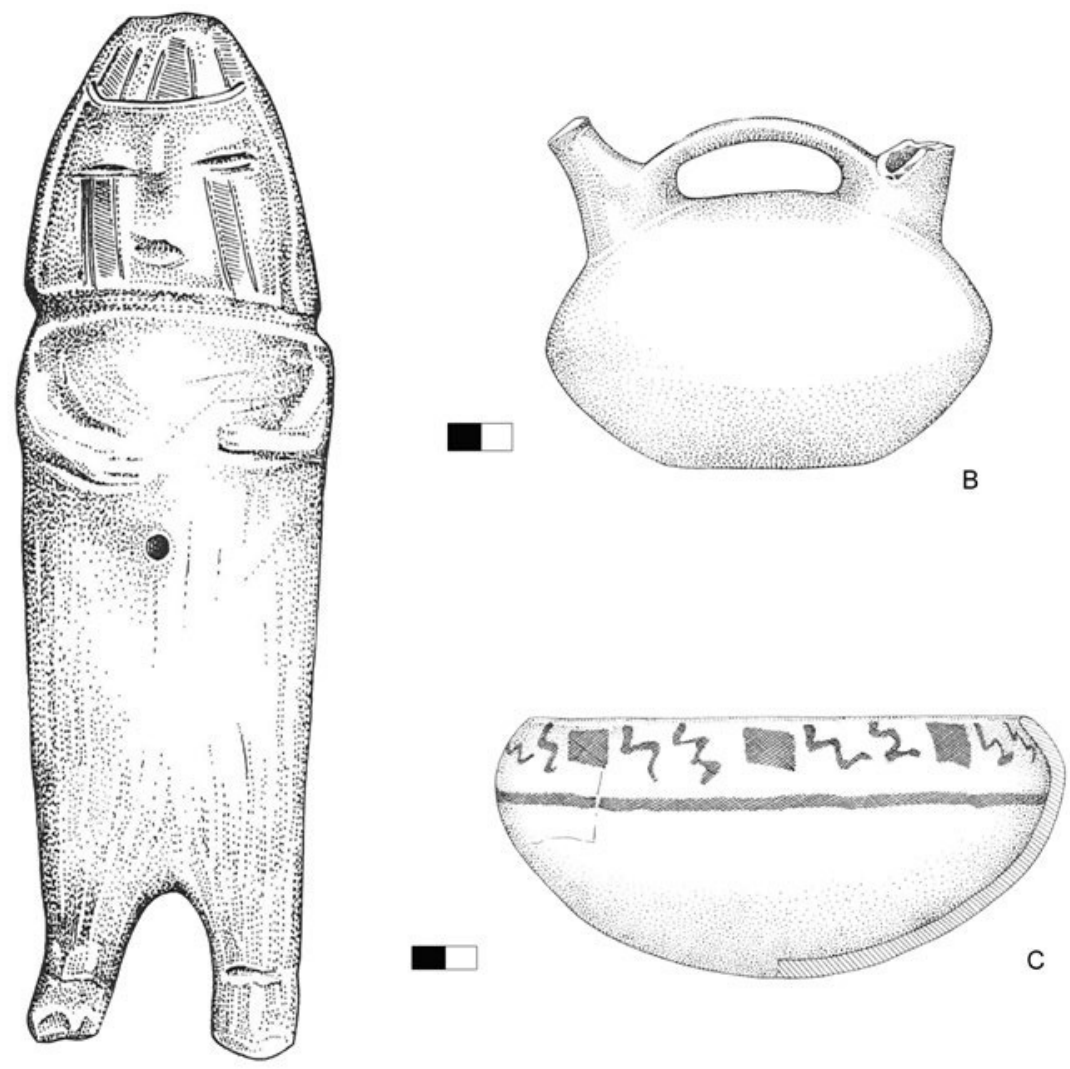

A

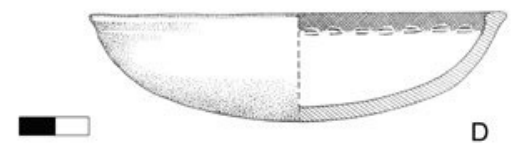

Fig. 7. Cerámica de Cerro Colorado sin analogía. A: figurina antropomorfa de Cerro Colorado (Esp. C-12540; 13/52) - $N^{\circ}$ de cat.: 14; B: botella con asa puente (Esp. C-16217; 12/5279) - $N^{\circ}$ de cat.: 30; C: cuenco rojo sobre crema Cochachongos (Esp. C-16114; 12/5256) - $N^{\circ}$ de cat.: 28; D: plato (Esp. C-15970; 12/8234) (grupo I) - No de cat.: 55.

Es probable que una situación similar se presente también en los ajuares textiles, pero aún hacen falta los estudios pertinentes. La cronología relativa sugiere un período de traslape en el uso funerario de la cima de Cerro Colorado (Cavernas) y de las faldas septentrionales (Necrópolis). Hay materiales del Horizonte Temprano 10 en ambas áreas. La cerámica analizada carece de parecido con la alfaría procedente de la arquitectura monumental del valle de Chincha, a la que Nigra (2017) caracteriza como Pinta y la ubica en su Paracas Medio, que correspondería al Horizonte Temprano 5-7. No cabe duda de que la fase Cavernas de Paracas, siendo posterior al abandono de las Huacas Soto y El Mono en Chincha, es más bien contemporánea con el desarrollo del centro ceremonial de Ánimas Altas-Ánimas Bajas en el valle Bajo de Ica, durante el Horizonte Temprano 7/8-10 (Bachir Bacha y Llanos 2015). 
Hay diferencias en el repertorio formal y en las técnicas de cocción y de acabado notorias entre la cerámica procedente de las hoyas de Callango y Ocucaje, cuyos contados especimenes decorados se han registrado en Cerro Colorado, y el componente Topará (Jahuay, Chongos e influenciado por Topará). Durante la fase posterior a Cavernas —Paraca Necrópolis_-, la variabilidad estilística disminuye drásticamente en los ajuares cerámicos (Tello 2012). El estilo Topará Chongos se impone (Massey 1986, 1992). La situación similar se observa en el vecino valle de Pisco, donde se registra la construcción de centros ceremoniales con la arquitectura pública monumental, asociada a los hallazgos de la cerámica topará de fases Jahuay, Chongos y Carmen (Peters 2015). La presencia de formas monócromas con engobe marrón, formalmente Nasca 1, es muy limitada numéricamente. En cambio, se incrementa la variabilidad estilística en los ajuares textiles. La mayoría de las textiles podría proceder de las mismas zonas de las que anteriormente provenía la cerámica. En todo caso, el bajo número de hallazgos de ofrendas de cerámica en ambas fases sugiere que las ofrendas de recipientes de cerámica no definían el rango social del individuo, a diferencia de vestidos y tocados.

Los resultados del análisis no aportan evidencias a favor de la existencia de una tradición alfarera originaria de la bahía de Paracas, que podría ser llamada Paracas Cavernas. El material cerámico encontrado en las tumbas de cámara que dieron origen al nombre de la fase comprende varios estilos importados. El grupo mayoritario en la hipotética fase Cavernas, nuestro grupo 2, comprende especímenes decorados producidos en Callango o bajo influencia de los alfareros del bajo Ica y también vasijas de la parte alta del valle bajo. Son estos ceramios que sirvieron a Tello (1959; Tello y Mejía Xesspe 1979) para proponer la existencia de una cultura Paracas. El estilo absolutamente dominante en la fase Necrópolis, el estilo Topará, está presente también en la fase Cavernas - nuestros grupos 1 y 3-, y en cantidades relevantes, 30\% de la muestra. Los tres grupos fueron aperentemente registrados en la misma cámara funeraria (véanse por ejemplo las cavernas V y VI). La misma situación de coexistencia de estilos al interior del mismo fardo se observa en la hipotética fase Necrópolis (Peters 2010 y este volumen).

Nuevas evidencias invitan a revisar el clásico modelo de Paracas como cultura regional y sustituirlo por otro, mejor respaldado por las evidencias. En la opinión de Makowski (2001, 2004, 2010), la situación en cuanto al desarrollo de tecnologías alfareras, a los mecanismos de poder y a los potenciales movimientos de grupos humamos e ideas, cambió sustancialmente en la costa centro-sur luego del ocaso de Chavín de Huántar, en el transcurso del siglo V cal. a.C. Durante las fases 5-10 del Horizonte Temprano, varios centros compitieron entre sí en el área de interacción, que parece haberse extendido entre los valles costeños de Mala y Acarí, abarcando también, por lo menos en el caso de los valles de Palpa e Ica (Lane et al. 2018), las cabeceras (Reindel e Isla, este volumen). La existencia de dichos centros está sugerida por la envergadura de la arquitectura monumental en el valle bajo de Chincha (Horizonte Temprano 5-7), y en las Ánimas Altas/Bajas en la hoya de Callango-Ica (Horizonte Temprano 7/8-10), en el valle bajo de Pisco (transición Horizonte Temprano/Período Intermedio Temprano). Hay una probable relación entre la difusión de la tecnología alfarera Topará, el abandono de las Animas Altas/Bajas, y el inicio de las actividades constructivas en Cahuachi, al comienzo del Período Intermedio Temprano. Es no solo probable, sino también en parte comprobado, que cada uno de los cuatro centros ceremoniales mencionados, ubicados cada uno en un valle diferente, ha condicionado la formación de un estilo particular, cuya popularidad regional dependía del prestigio político y religioso de su zona de origen durante un tiempo dado, no mayor de tres siglos. De este modo los traslapes sucesivos de estilo Pinta (Chincha), con Ocucaje (7/8-10; Ica), de este con Topará (Pisco) y de Topará con Nasca (Nasca-Cahuachi) se explicaría por la formación, auge y ocaso de centros religiosos ubicados en los valles vecinos e interactuantes. Hay que obsrevar, sin embargo, que a juzgar por las evidencias materiales, hay más diferencias que similitudes en materia social, religiosa (iconografía y arquitectura) y posiblemente también política en la costa centro-sur, cuando se compara respectivamente a las fases denominadas Paracas Temprano y Medio, anteriores a la fundación del asentamiento en la 
cima y faldas de Wari-Kayan-Cerro Colorado de Paracas (aproximadamente 800-300 a.C.), con la fase Paracas Tardío (300 a.C.-100 d.C.). Viendolo de este modo, ni el estilo Paracas se origina en la bahía de Paracas, ni la cultura Paracas — marcada por la interaccion con el mundo Chavín-, debe ser entendida como el origen directo de las realidades sociales y tradiciones religiosas, cuyas expresiones materiales Tello descubrió en el sitio de Paracas.

\section{Notas}

1 Menzel, Dawson y Rowe (1964: 267-268), diferencian 18 variantes de botellas (asa-estribo, botellas silbadoras de 1 cuerpo en 2 variantes y de 2 cuerpos, botellas con asa-puente que une el gollete con la protoma de ave silbadoras y no silbadoras, con protoma humana, con protoma de zorro, botella asa-puente de dos golletes en 3 variantes, botella con engobe blanco), 1 variante de canchero, 1 de taza, 2 tipos de tazones-ralladores, 3 tipos de cuencos, 1 tipo de olla, 1 tipo de olla sin cuello y 4 instrumentos musicales. Entre las técnicas distinguen 3 variantes de la decoración negativa (obtenida mediantes la oxidación diferenciada en la superficie), incisa sin pintar en 6 variantes, incisa pintada con pintura resinosa en 10 variantes, pintada en 2 variantes, engobada de rojo, blanco y con engobes multicolores.

2 Las fases 1 y 2 fueron definidas a partir de cerámica de colecciones y provienen de diferentes períodos de tiempo (Burger 1988: 107): tres piezas agrupadas alrededor de la botella Olsen para la fase 1 y otras dos alrededor de la botella Wielgus para la fase 2 ; se decía que estas últimas procedían de un mismo entierro; otras tres piezas de Brooklyn Museum de un entierro en Chiquerillo relacionan las fases 1 y 2 con la 3 (op.cit.: 9-19).

3 Los analisis de la cerámica fueron presentados por la primera vez en la tesis de maestría escrita bajo la tutoría del dr. Krzysztof Makowski y del dr. Mariusz Ziółkowski. La tesis fue sustentada en la Universidad de Varsovia en 2004.

4 En su terminología un entierro en pozo o en fosa debería llamarse «tumba» a diferencia de un entierro en cámara, llamado «caverna».

\section{REFERENCIAS}

Bachir Bacha, A.

2007 Dinámica y desarrollo de un centro ceremonial andino. El caso de Cahuachi, Arqueología y Sociedad 18, 69-94.

2018 El edificio de los frisos de Ánimas Altas. Ser paracas en el valle bajo de Ica, Boletín de Arqueología PUCP 22, 191-225. https://doi.org/10.18800/boletindearqueologiapucp.201701.008

Bachir Bacha, A. y O.D. Llanos Jacinto

2011 Arqueología e iconografía de los textiles Paracas descubiertos en Animas Altas, Ica, Perú, en: V. Solanilla (ed.), Actas de las V Jornadas Internacionales sobre Textiles Precolombinos, 211-230. http://halshs.archivesouvertes.fr/view_by_stamp.php?\&halsid=fn8e5941t3ulghtal $41 \mathrm{j} 43 \mathrm{sm} 41 \&$ label=SHS\&langue=fr\&a ction_todo=view\&id=halshs-00733891\&version=1\&view=extended_view

2015 ¿Hacia un urbanismo paracas en Ánimas Altas/Ánimas Bajas (valle de Ica)? Boletín de Arquelogía PUCP 17, 169-204.

Beresdorf-Jones, D., C. Alarcón, S. Arce, A. Chepstow-Lusty, O. Whaley, F. Sturt, M. Gorriti, O. Portocarrero y L. Cadwallader

2010 Ocupación y subsistencia del Horizonte Temprano en el contexto de cambios ecológicos de largo plazo

[2009] en las cuencas de Samaca y Ullujaya, valle bajo de Ica. Boletín de Arqueología PUCP 13, 237-259.

Browman, D. L.

1970 Early Peruvian peasants: The culture history of a central highland valley, tesis de doctorado, Department of Anthropology, University of California, Berkeley. 
1977 External relationships of the Early Horizon ceramic styles from the Jauja-Huancayo Basin, Junin, $E l$ Dorado 11 (1), 1-23.

Browne, D. M.

1992 Further archaeological reconnaissance in the Province of Palpa, Department of Ica, Peru, en: N. Saunders (ed.), Ancient America. Contributions to New World archaeology, Oxbow Monograph 24, Oxbow Books, Oxford.

\section{Browne, D. M. y J.P. Baraybar}

1988 An archaeological reconnaisance in the Province of Palpa, Department of Ica, Peru, en: N. Saunders y O. Olivier de Montmollin (eds.), Recent studies in pre-Columbian archaeology, 299-325, BAR International Series 42, Oxford.

\section{Burger, R.}

1984 The prehistoric occupation of Chavin de Huantar, Peru, Publications in anthropology 14, University of California Press, Berkeley.

1985 Concluding remarks: Early Peruvian civilization and its relation to the Chavin Horizon, en: C. Donnan (ed.), Early ceremonial architecture in the Andes, 269-289, Dumbarton Oaks Research Library and Collection, Washington, D.C.

1988 Unity and heterogeneity within the Chavin Horizon, en: R. Keatinge (ed.), Peruvian prehistory 99-144, Cambridge University Press, Cambridge.

1992 Chavin and the origins of Andean civilization, Thames and Hudson, Londres.

1993 The Chavin Horizon: Chimera or socioeconomic metamorphosis?, en: D. Rice (ed.), Latin American Horizons 41-82; A symposium at Dumbarton Oaks, Dumbarton Oaks Research Library and Collection, Washington, D.C.

2009 The life and writings of Julio C. Tello: America's first indigenous archaeologist, University of Iowa Press. https://doi.org/10.2307/j.ctt20mvf96

2013 In the realm of the Incas: An archaeological reconsideration of household exchange, long-distance trade, and marketplaces in the pre-Hispanic Central Andes, en: K. Hirth y J. Pillsbury (eds.), Merchant, markets and exchange in the pre-Columbian world, 319-334, Dumbarton Oaks Pre-Columbian Symposia and Colloquia, Dumbarton Oaks, Washington, D.C.

Canziani, J.

1992 Arquitectura y urbanismo del Período Paracas en el valle de Chincha, Gaceta Arqueológica Andina 22, 87-117.

2012 Ciudad y territorio en los Andes. Contribuciones a la historia del urbanismo prehispánico, 2da edición, Fondo Editorial PUCP, Lima

2015 Arquitectura, urbanismo y transformaciones territoriales del Período Paracas en el valle de Chincha, Boletin de Arqueología PUCP 17, 103-132.

\section{Carrillo, $\mathrm{H}$.}

2009 La presencia topará en el valle de Lurín, en: R. Burger y K. Makowski (eds.), Arqueología del Periodo Formativo en el valle de Pachacamac, 427-488, Fondo Editorial PUCP, Lima.

\section{Conklin, W. J.}

1971 Chavin Textiles and the Origins of Peruvian Weaving. Textile Museum Journal, 3 (2): 13-19.

1978 The Revolutionary Weaving Inventions of the Early Horizon. Nawpa Pacha, 16: 1-12, pls. I-VI. https:// doi.org/10.1179/naw.1978.16.1.001

\section{Cordy-Collins, A.}

1976 An iconographic study of Chavin textiles from the south coast of Peru: The discovery of a pre-Columbian catechism, tesis de doctorado, Department of Archaeology, University of California, Los Angeles, University Microfilms, Ann Arbor.

1977 Chavin art: Its shamanic/hallucinogenic origins, en: A. Cordy-Collins y J. Stern (eds.), Pre-Columbian art history, 353-362, Peek Publications, Palo Alto.

1979a Cotton and the staff god: Analysis of an ancient Chavin textile, en: A. P. Rowe, E.P. Benson y A. L. Schäffer (eds.), The Junius B. Bird pre-Columbian textile conference, 51-60, Textile Museum y Dumbarton Oaks, Washington, D.C.

1979b The dual divinity concept in Chavin art, El Dorado 3, 1-31. 
1980 An artistic record of the Chavin hallucinatory experience, Masterkey 54, 84-93.

1983 The dual divinity concept in Chavin art, Museum of Anthropology, Miscellaneous Series 48: 42-72, University of Northern Colorado, Greeley.

Daggett, R. E.

1991 Paracas: Discovery and controversy, en: A. Paul (ed.), Paracas: Art and architecture. Object and context in south coastal Peru, University of Iowa Press, Iowa.

Delgado, $\mathrm{M}$.

2007 Investigaciones arqueológicas en Villa El Salvador: secuencia cerámica en contextos funerarios, tesis de licenciatura, Facultad de Letras y Ciencias Humanas, Pontificia Universidad Católica del Perú, Lima.

DeLeonardis, L.

1997 Paracas settlement in Callango, lower Ica Valley, Ist Millenium B.C., Peru, tesis de doctorado, Department of Anthropology, School of Art and Sciences, The Catholica University of America, Washington, D.C.

2005 Early Paracas cultural contexts: New evidence from Callango, Andean Past 7, 27-55.

Dawson, L. E.

1964 Slip casting: A ceramic technique invented in ancient Peru, Nawpa Pacha 2, 107-112. https://doi.org/ 10.1179/naw.1964.2.1.002

Dobres, M. A.

2000 Technology and Social Agency: Outlining a practice framework for archaeology, Blakwell.

Dulanto, J.

2015 Puerto Nuevo: redes de intercambio a larga distancia durante la primera mitad del primer milenio antes de nuestra era, Boletín de Arquelogía PUCP 17, 103-132.

Dwyer, E. B.

1979 Early Horizon tapestry from south coastal Peru, en: A. Pollard Rowe, E. P. Benson y A-L. Schaffer (eds.), The Junius B. Bird pre-Columbian textile conference, 61-82, Textile Museum y Dumbarton Oaks, Washington, D.C.

Dwyer, E. B., y J. P. Dwyer

1975 The Paracas cemeteries: Mortuary patterns in a Peruvian south coastal tradition, en: E. Benson (ed.), Death and afterlife in pre-Columbian America 145-161, Dumbarton Oaks, Washington, D.C.

Dwyer J. P.

1971 Chronology and iconography in Late Paracas and Early Nasca textile designs, tesis de doctorado, Department of Anthropology, University of California, Berkeley.

1979 The chronology and iconography of Paracas-Style textiles, en: A. Pollard Rowe, E. P. Benson y A-L. Schaffer (eds.), The Junius B. Bird pre-Columbian textile conference, 105-128, Textile Museum y Dumbarton Oaks, Washington, D.C.

Engel, F.

1966 Paracas: cien siglos de cultura peruana, Editorial Juan Mejía Baca, Lima.

1987 De las begonias al maiz: vida y producción en el Perú antiguo, Universidad Nacional Agraria, La Molina.

García, R.

2010 Puerto Nuevo y los orígenes de la tradición estilístico-religiosa Paracas, Boletín de Arqueología PUCP 13, [2009] 159-186.

García, R. y J. Pinilla

1995 Aproximación a una secuencia de fases con cerámica temprana de la region de Paracas. In: Current Research in Andean Antiquity. Journal of the Steward Anthropological Society (Ari Zighelboim \& Carol Barnes, eds.), 23 (1, 2), 43-82, Urbana.

Gayton, A. H. y A. Kroeber

1927 The Uhle pottery collections from Nazca; University of California Publications in American Archaeology and Ethnology 24 (1), 1-46. 


\section{Goldhausen, M.}

2013 Spätformativ- und regionalzeitliche Besiedlung im Trockental Orcón-Pacaybamba an der Zentralen Küste von Peru (450 v. Chr. - 750 n.Chr.) Ein Beitrag zur Problematik der Entstehung früher Staatlichkeit in den Zentralen Anden. Tésis doctoral, Freie Universität Berlin (September 2012), Berlín.

\section{Hegmon, $M$.}

1998 Technology, style and social practices, en: M. Stark (ed.), The Archaeology of social boundaries, 264-280, Smithsonian Institution Press, Washington/Londres.

Hill, K., B. Nigra, H. Tantaleán y T Jones

2012 Cerro Gentil. A Paracas mound site in the Chincha Valley, Peru, Backdirt, 93-103, Cotsen Institute of Archaeology.

Isla, J.

2009 From hunters to regional lords: Funerary practices in Palpa, Peru, en: M. Reindel y G. Wagner (eds.), New technologies for archaeology: Multidisciplinary investigations in Palpa and Nasca, Perú, 119-139; Natural Science in Archaeology, Springer, Berlin, Heidelberg.

Isla, J., M. Reindel y J.C. De La Torre

2003 Juaranga, un sitio Paracas en el valle de Palpa, costa sur del Perú, Beiträge zur Allgemeinen und Vegleichenden Archäologie 23, 227-274.

Isla, J. y M. Reindel

2015 Jauranga: una aproximación a la ocupación Paracas en el valle de Palpa. Boletín de Arqueología PUCP 17, 231-262.

Kaulicke, P.

2015 Paracas y Chavín: variaciones sobre un tema longevo, Boletín de Arqueología PUCP 17, 263-290.

Kaulicke, P., L. Fehren-Schmitz, M. Kolp-Godoy, P. Landa, O. Loyola, M. Palma, E. Tomasto-Cagigao, C. Vergel y B. Vogt

2010 Implicancias de un área funeraria del Período Formativo Tardío en el departamento de Ica, Boletín de Arqueología PUCP 13, 259-288.

Kroeber, A. L.

1944 Peruvian Archaeology in 1942, Viking Fund Publications in Anthropology 4, Viking Fund Publications, New York.

1953 Paracas Cavernas and Chavin; University of California Publications in American Archaeology and Ethnology 40 (8), 313-328, University of California Press, Berkeley.

Lane, K., O. Huaman, L. Coll, A. Pullen, D. Beresdorf-Jones y C. French

2018 De fronteras y enclaves: la presencia Nasca en la sierra de Ica (260 a.C.-640 d.C.), Boletín de Arqueología PUCP 22, 117-132. https://doi.org/10.18800/boletindearqueologiapucp.201701.005

Lanning, E. P.

1960 Chronological and cultural relationships of early pottery styles in ancient Peru; tesis de doctorado, University of California, Berkeley.

Lechtman, $\mathrm{H}$.

1975 Style in technology: some early thoughts, en: H. Lechtman y R. Merrill (eds.), Material culture: Styles, organization, and dynamics of technology (Proceedings of the American Ethnological Society), West Pub. Co., St. Paul.

Leon, E.

2007 Lascas de obsidiana tipo kombewa de Wari Kayan, en: M. Frame, J. Isla, E. León, A. Peters, M. Reindel y C. Thays (eds.), Hilos del pasado. Aporte francés al legado Paracas, 75-77, Instituto Nacional de Cultura, Lima.

2013 La cultura Paracas, en: Paracas 11-26, Museo Nacional de Arqueología, Antropología e Historia del Perú, Ministerio de Cultura, Lima.

Lumbreras, L. G.

1969 De los pueblos, de las culturas y las artes del Antiguo Perú, Moncloa Campodónico, Lima. 
Makowski, K.

2000 Los seres sobrenaturales en la iconografía Paracas y Nazca, Los dioses del antiguo Peru, 277-311, Banco de Crédito, Lima.

2001 Las civilizaciones prehispánicas en la Costa Central y Sur, Historia de la cultura peruana 1, 163-243, Fondo Editorial del Congreso del Perú, Lima.

2004 Primeras civilizaciones, Enciclopedia Temática del Perú, vol. IX, Ediciones El Comercio, Lima.

2010 Los hombres guerreros, las mujeres alfareras: cambios sociales tras el ocaso de Chavín, en: K. Makowski (ed.), Señores de los Imperios del Sol, 1-18, Ediciones Banco de Crédito.

Makowski, K., P. Castro De La Mata, G. Escajadillo, M. Jimenez y E Tomasto-Cagigao

2012 Comportamientos funerarios y roles sociales en una sociedad guerrera post-Chavín: Tablada de Lurín, en: K. Makowski, P. Castro de la Mata, G. Escajadillo, M. Jimenez y E. Tomasto-Cagigao (eds.), Ajuares funerarios de los cementerios prehispánicos en Tablada de Lurín (Periodo Formativo Tardio, Lima, Perú), Academia Polaca de Ciencias y Letras, Pontificia Universidad Católica del Perú, Cracovia.

Massey, S.

1983 Antiguo centro Paracas-Animas Alta, en: J.A. de Lavalle y W. Lang (eds.), Culturas precolombinas: Paracas. Colección arte y tesoros del Perú, 134-160, Banco de Crédito, Lima.

1986 Sociopolitical change in the Upper Ica Valley, B.C. 400 to 400 A.D., Regional States on the South Coast of Peru; tesis de doctorado, Department of Archaeology, University of California, Los Angeles; University Microfilms, Ann Arbor.

1991a Paracas, en: S. Purin (ed.), Los Incas y el antiguo Perú: 3,000 años de historia, Sociedad Estatal Quinto Centenario, Madrid.

1991b Social and political leadership in the lower Ica Valley: Ocucaje phases 8 and 9, en: A. Paul (ed.), Paracas: Art and architecture. Object and context in south coastal Peru University of Iowa Press, Iowa.

1992 Investigaciones arqueológicas en el valle alto de Ica: Período Intermedio Temprano 1 y 2, en: D. Bonavia (ed.), Estudios de Arqueología Peruana, FOMCIENCIAS, Lima.

Matsumoto, Y. y Y. Cavero

2013 Una aproximación cronológica del centro ceremonial de Campanayuq Rumi, Ayacucho, Boletín de Arqueología PUCP 13, 259-288.

Medina, M.Y.

2013 Estudio de contenido asociado a 37 individuos de la V Caverna en la segunda terraza del Cerro Colorado, en: Paracas, 29-39, Museo Nacional de Arqueología, Antropología e Historia del Perú, Ministerio de Cultura, Lima.

Menzel, D.

1971 Estudios arqueológicos en los valles de Ica, Pisco, Chincha y Cañete, Arqueología y Sociedad 6, 1-16, Universidad Nacional Mayor de San Marcos, Lima.

Menzel, D., J. H. Rowe y L.E. Dawson

1964 The Paracas pottery of Ica; A study in style and time, Publications in American Archaeology and Ethnology 50, University of California, Berkeley.

Muelle, J. C.

1931 Paracas: nuevas excavaciones en Cerro Colorado, El Comercio, 16-17, 4 de octubre.

Nigra, B. T.

2017 Huaca Soto and the evolution of Paracas communities in the Chincha Valley, Peru, teis de doctorado, University of California, Los Angeles, Los Angeles.

Orefici, G.

1998 Max Uhle y las investigaciones arqueológicas en la región de Nasca, Indiana 15, 217-256.

2012 Cahuachi. Capital teocrática Nasca, vol.1 y 2, Universidad San Martín de Porres, Lima.

Palacios, J.

1988 La secuencia de la cerámica temprana del valle de Lima en Huachipa, Gaceta Arqueológica Andina 16, 13-24.

1999 La tradición «Cerro» en Huachipa, valle de Rímac, tesis de licenciatura, Universidad Nacional Mayor de San Marcos, Lima. 
Paul, A.

1980 Paracas ritual attire: Symbols of authority in ancient Peru, tesis de doctorado, Department of Art History, University of Texas, Austin.

1982 The chronological relationship of the Línear, Block Color and Broad Line Styles of Paracas embroidered images, en: A. Cordy-Collins (ed.), Pre-Columbian art history, 255-277, Peek Publications, Palo Alto.

1986 Continuity in Paracas textile iconography and its implications for the meaning of Línear Style images, en: A. Pollard Rowe, E. Benson y A-L. Schaffer (eds.), The Junius B. Bird pre-Columbian textiles conference, 81-99, Textile Museum y Dumbarton Oaks, Washington, D.C.

1990 Paracas ritual attire: Symbols of authority in ancient Peru, University of Oklahoma Press, Norman.

1991 Paracas: An ancient cultural tradition on the South Coast of Peru, en: A. Paul (ed.), Paracas: Art and architecture. Object and context in south coastal Peru, University of Iowa Press, Iowa.

Peters, A. H.

19861 Pachinga: Habitation and necropolis in the Lower Pisco Valley, Paper presented at the 51st Annual Meeting of the Society for American Archaeology, New Orleans.

1989- Chongos: sitio paracas en el valle de Pisco, Gaceta Arqueológica Andina 16, 30-34.

1988

1997 Paracas, Topará and early Nasca: Ethnicity and society on the south central Andean coast; tesis de doctorado, Department of Anthropology, Cornell University, Ithaca.

2010 Paracas: liderazgo social, memoria histórica y lo sagrado en la necrópolis de Wari Kayân, en: K. Makowski (ed.), Señores de los imperios del Sol, 211-224, Banco de Crédito del Perú, Lima.

2012a Identity, innovation and textile exchange practices at the Paracas Necropolis, 2000 BP, Textile Society of America Symposium Proceedings, Paper 726. http://digitalcommons.unl.edu/tsaconf/726

2012b Diversidad en el componente textil y modelos de las relaciones sociales: un ejemplo de Paracas Necrópolis, Actas de los V Jornadas Internacionales sobre Textiles Precolombinos, 29 noviembre-1 diciembre, 2010, Centre D’Estudis Precolombins, Barcelona.

Ravines, R.

1970100 años de arqueología en el Perú, Instituto de Estudios Peruanos, Lima.

Reindel, $\mathrm{M}$.

2009 Life at the edge of the desert. Archaeological reconstruction of the settlement history of the Valleys of Palpa, Perú, en: M. Reindel y G. Wagner (eds.), New technologies for archaeology: Multidisciplinary investigations in Palpa and Nasca, Perú, 439-461, Natural Science in Archaeology, Springer, Berlin/Heidelberg. https://doi.org/10.1007/978-3-540-87438-6_25

Reindel, M. y J. Isla

2008 Evidencias de las culturas tempranas en los valles de Palpa, costa sur del Perú, Boletín de Arqueología PUCP 10, 237-284.

2010 El Período Inicial en Pernil Alto, Palpa, Costa Sur del Perú, Boletín de Arqueología PUCP 13, 259-288.

Reindel, M., J. Isla, D. Kupferschmidt y H. Otten

2010 La pala investigadora de Max Uhle. Sus aportes a la cronología de la costa sur a la luz de las investigaciones recientes, en: P. Kaulicke, M. Fischer, P. Masson y G. Wolff, (eds.), Max Uhle (1856-1944). Evaluaciones de sus investigaciones y obras, 253-280, Fondo Editorial PUCP, Lima.

Rick, J. W., C. Mesia, D. Contreras, S. Kembel, R. Rick, M. Sayre y J. Wolf

2010 La cronología de Chavín de Huántar y sus implicancias para el Período Formativo, Boletín de Arqueología PUCP 13, 87-132.

Rodriguez Kembel, S. y H. Haas

2013 Radiocarbon dates from the monumental architecture at Chavín de Huántar, Perú, Journal of Archaeological Method and Theory 22(2), 345-427. https://doi.org/10.1007/s10816-013-9180-9

Roe, P.

2008 How to build a raptor: Why the Dumbarton Oaks «Scaled Cayman» Callango Textile is Really a Chavín Jaguaroid Harpy Eagle, en: W. Conklin y J. Quilter (eds.), Chavin. Art, architecture and culture, 181-216, Monograph 61, Cotsen Institute of Archaeology, University of California, Los Angeles. https://doi. org/10.2307/j.ctvdmwx21.13 
Rowe, J. H.

1958 La seriación cronológica de la cerámica de Paracas elaborada por Lawrence E. Dawson, Revista del Museo Regional de Ica 9 (10), 9-21.

1961 Stratigraphy and Seriation, American Antiquity 26, 324-330. https://doi.org/10.2307/277399

1962a Worsaae's law and the use of grave lots for Archaeological dating, American Antiquity 28, 129-137. https://doi.org/10.2307/278369

1962b Stages and periods in archaeological interpretation, Southwestern Journal of Anthropology 18 (1), 40-54. https://doi.org/10.1086/soutjanth.18.1.3629122

1967a Form and meaning in Chavín art, en: J.H. Rowe y D. Menzel (eds.), Peruvian Archaeology. Selected Readings 72-103, Peek Publ., Palo Alto.

$1967 \mathrm{~b}$ An interpretation of radiocarbon measurements on archaeological samples from Peru, en: J.H. Rowe y D. Menzel (eds.), Peruvian archaeology. Selected readings, 16-30, Peek Publ., Palo Alto.

Sawyer, A. R.

1961 Paracas and Nazca iconography, en: S. Lothrop et al. (eds.), Essays in pre-Columbian art and archaeology, 269-298, Harvard University Press, Cambridge.

1966 Ancient Peruvian ceramics: The Nathan Cummings collection, Metropolitain Museum of Art, Nueva York.

1972 The Feline in Paracas art, en: E. Benso (ed.), The Cult of the Feline: A Conference on Pre-Columbian Iconography, 91-115, Dumbarton Oaks, Washington, D.C.

Silva, J. E. y R. S. García

1997 Huachipa-Jicamarca: cronología y desarrollo sociopolítico en el Rímac, Bulletin de l'institut Francais d'etudes andines 26 (2), 195-228.

Silverman, $\mathrm{H}$.

1991 Paracas problem: Archaeological perspectives, en: A. Paul (ed.), Paracas Art and Architecture. Object and Context in South Coastal Perú, 347-415, University of Iowa Press, Iowa City.

1994a Paracas in Nazca: New data on the Early Horizon occupation in the rio Grande de Nazca Drainage, Peru, Latin American Antiquity 5 (4), 359-382. https://doi.org/10.2307/971822

$1994 \mathrm{~b}$ Cahuachi in the Ancient Nasca World, University of Iowa Press, Iowa City.

1995 Recent archaeological investigations on the South Coast of Peru: Critique and prospects, Journal of the Steward Anthropological Society 23 (1 y 2), 13-41.

1996 Contextualizando la Muerte en los cementerios de Paracas, en: L. Millones (ed.), Al final del camino, 1-19, SIDEA, Lima.

1997 The first field season of excavations at the Alto del Molino site, Pisco Valley, Peru, Journal of Field Archaeology 24, 441-457. https://doi.org/10.1179/jfa.1997.24.4.441

2002a Differentiating Paracas Necrópolis and Early Nazca textiles, en: W. H. Isbell y H. Silverman (eds.), Andean archaeology ii: Art, landscape and society, 71-105, Kluwer Academic/Plenum Publishers, New York.

2002b Ancient Nasca settlement and society, University of Iowa Press, Iowa City.

2009 Comparaciones y contrastes entre la costa sur y la costa central del Perú durante el Período Formativo, en: R. Burger y K. Makowski (eds.), Arqueología del periodo formativo en el valle de Pachacamac, 427-488, Fondo Editorial PUCP, Lima.

Silverman, H. y D. Proulx

2002 The Nasca. Peoples of America; Blackwell Publ., Malden, Oxford.

Splitstosser, J., D. Wallace y M. Delgado

2010 Nuevas evidencias de textiles y cerámica de la época Paracas Temprano en Cerillos, valle de Ica, Perú, Boletin de Arqueología PUCP 13, 209-236.

Strong, W.

1957 Paracas, Nazca and Tiahuanacoid cultural relationships in south coastal Peru, Memoirs of the Society for American Archaeology 13, Salt Lake City.

Tabio, E.

1965 Excavaciones en la Costa Central del Perú (1955-58), Academia de Ciencias, Departamento de Investigaciones Antropológicas. Instituto Nacional de Cultura, La Habana.

Tantaleán, H., C. Stanish, M. Zegarra y B. Nigra

2015 Paracas en el valle de Chincha: nuevos datos y explicaciones, Boletín de Arqueología PUCP 17, 31-56. https://doi.org/10.18800/boletindearqueologiapucp.201701.003 
Tantaléan, H., C. Stanish, K. Pérez y A. Rodriguez

2018 Las ocupaciones paracas y topará en Cerro del gentil, valle de Chincha, Boletín de Arqueología PUCP 22, 61-89.

Tellenbach, $\mathrm{M}$.

1998 Chavin: investigaciones acerca del desarrollo cultural Centro-Andino en las épocas Ofrendas y Chavin-Tardio, vols.1 y 2, Sociedad Polaca de Estudios Latinoamericanos y Misión Arqueológica Andina, Universidad de Varsovia, Varsovia.

Tello, J. C.

1928 Los descubrimientos del Museo de Arqueología Peruana en la peninsula de Paracas, Atti del XXU Congreso Internazionale degli Americanisti I, 679-690, Roma.

1929 Antiguo Perú. Primera época, Comisión Organizadora del Segundo Congreso Sudamericano de Turismo, Lima.

1942 Origen y desarrollo de las civilizaciones prehistóricas andinas, Librería e Imprenta Gil, Lima.

1959 Paracas. Primera Parte, Publicación del Proyecto 8b del Programa 1941-1942 del Institute of Andean Research, Empresa Gráfica T. Scheuch S.A., Lima.

1960 Chavin. Cultura matriz de la civilización andina, Publicación Antropológica del Archivo «Julio C. Tello» de la Universidad Nacional Mayor de San Marcos 2, Lima.

1967 Páginas Escogidas, Universidad Nacional Mayor de San Marcos, Lima.

2009 Paracas Cavernas, Cuaderno de Investigación del Archivo Tello 7, C. Sotelo Sarmiento (ed.), Museo de Arqueología y Antropología de la Universidad Nacional Mayor de San Marcos, Lima.

2012 Paracas. Wari Kayan, Cuaderno de Investigación del Archivo Tello 9, C. Sotelo Sarmiento (ed.), Museo de Arqueología y Antropología de la Universidad Nacional Mayor de San Marcos, Lima.

Tello, J. C. y T Mejia Xesspe

1979 Paracas. Segunda Parte: cavernas y necropólis, Universidad Nacional Mayor de San Marcos, Lima.

Uhle, $M$.

1913 Zur Chronologie der alten Culturen von Ica, Journal de la Société des Americanistes de Paris 10 (2), 341-367. https://doi.org/10.3406/jsa.1913.2864

Unkel, I. y B. Kromer

2009 The clock in the corn cob: On the development of a chronology of the Paracas and Nasca Period based on radiocarbon dating, en: M. Reindel y G. Wagner (eds.), New technologies for archaeology: Multidisciplinary investigations in Palpa and Nasca, Perú, 439-461, Natural Science in Archaeology, Springer, Berlin/ Heidelberg.

Wallace, D.

1960 Early Paracas textile techniques, American Antiquity 26 (2), 279-281. https://doi.org/10.2307/276210

1962 Cerrillos, an Early Paracas site in Ica, Peru, American Antiquity 27 (3), 303-314. https://doi. org/10.2307/277797

1963 Early Horizon ceramics in the Canete Valley of Peru, Nawpa Pacha 1, 35-38. https://doi.org/10.1179/ naw.1963.1.1.003

1971 Sitios arqueológicos del Perú: Valles de Chincha y de Pisco, Arqueológicas 13, 4-131.

1975 The analysis of weaving patterns: Examples from the early periods in Peru, en: P. Fiske (ed.), Irene Emery Roundtable on Museum Textiles, 1974, Proceedings Archaeological Textiles 101-116, Textile Museum, Washinton, D.C.

1979 The process of weaving development on the Peruvian south coast, en: A. Pollard Rowe, E. Benson y A.L. Schaffer (eds.), The Junius B. Bird pre-Columbian textile conference, 27-50, Textile Museum y Dumbarton Oaks, Washington, D.C.

1985 Paracas in Chincha and Pisco: A reappraisal of the Ocucaje sequence, en: P. Kvietok y D. H. Sandweiss (eds.), Recent studies in Andean prehistory and protohistory. Papers from the Second Annual Northeast Conference on Andean Archaeology and Ethnohistory, 67-94, Latin American Studies Program, Cornell University, Ithaca.

1986 The Topara tradition: An overview, en: D. H. Sandweiss y P. Kvietok (eds.), Perspectives on Andean Prehistory and Protohistory. Papers from the Third Annual Northeast Conference on Andean Archaeology and Ethnohistory, 35-47, Latin American Program, Cornell University, Ithaca, 
1991 A technical and iconographic analysis of Carhua painted textiles, en: A. Paul (ed.), Paracas: Art and architecture. Object and context in south coastal Peru, University of Iowa Press, Iowa City.

sf. $\quad$ Early Intermediate Period ceramics of the south central Peruvian coast, manuscrito.

Wallace, D., J. Splitstosser, M. Delgado, G. Katterman y W. Conklin

2005 Feathered effigy/burial from Cerillos, Ica Valley, en: V. Solanilla (ed.), Tejiendo sueños en el Cono Sur. Textiles andinos: pasado, presente y futuro. Actas del $51^{\circ}$ Congreso Internacional de Americanistas, Santiago, Chile 14-18 de julio de 2003 128-143, Grup d'Estudis Precolombins, Department d'Art de la Universitat Autonoma de Barcelona, Barcelona.

Würster, W.

1984 Asentamientos Prehispánicos en el Valle de Topará, Historia y Cultura 17, 7-16.

Yacovleff, E y J.C.Muelle

1932 Una exploración en Cerro Colorado, Revista del Museo Nacional 1,2, 31-102.

1934 Un fardo funerario Paracas, Revista del Museo Nacional 3(1-2), 63-153.

Young, $M$.

2018 De la montaña al mar: intercambio entre la sierra centro-sur y la costa sur durante el Horizonte Temprano. Boletin de Arqueologia PUCP 22, 9-34. https://doi.org/10.18800/boletindearqueologiapucp.201701.001

Ziolkowski, M., Pazdur, M., Krzanowski, A. \& Michczynski, A.

1994 Andes. Radiocarbon database for Bolivia, Ecuador and Peru, Andean Archaeological Mission of the Institute of Archaeology, Warsaw University, Gliwice Radiocarbon Laboratory of the Institute of Physics, Silesian Technical University, Warsaw/Gliwice.

\section{Fuentes de archivo, Instituto Riva Agüero PUCP, Lima:}

Mejía Xesspe, T. - Paracas 1925. Gastos de viaje de Mejía Xesspe. Información sobre estudio de las Cavernas I, II i III de Cerro Colorado.

Mejía Xesspe, T. - Informe de Cerro Colorado.

Mejía Xesspe, T. - Paracas 1927. Historia de las cavernas de Cerro Colorado y de las momias Nr 1 a 101 de las Grandes Necrópolis. 21 de noviembre a 3 de diciembre de 1927.

Mejía Xesspe, T. - Informe de trabajos 27.09 - 14.11 del 1927. Trabajos arqueológicos en la zona de, Paracas.

Mejía Xesspe, T. - Campamento de Cerro Colorado a 26 de octubre de 1927.

Mejía Xesspe, T. - Elementos culturales de Paracas.

Hurtado, A. - Informe de Hurtado sobre trabajos en Cerro Colorado (25 de setiembre a 7 de octubre 1927).

Hurtado, A. - Paracas 1928. Informe de Hurtado sobre los trabajos realizados en la Sección Central de las Grandes Necrópolis - cateo 99-100. 23 de enero a de febrero, 1928. 
Anexo. $\mathrm{N}^{\circ}$ de inventario (MNAAHP) de la cerámica analizada

1a Terraza
Tumba 3:
C-16022 (12/6564)
Tumba 8:
C-15867 (12/5291)
Tumba 11:
C-16235 (12/6560)
IIa Terraza
Caverna II:
C-15866 (13/341)
Caverna IV:
C-15816
Caverna V:
C-15899
C-15938
C-15944
C-15957
C-15763
C-15946
C-15954
C-15926

VI Caverna: C-16091 (12/6291) C-15755 (12/6338) C-16110 (12/6341) C-16117 (12/6342) C-15930 (12/5239)
Tumba 8:

C-15929 (12/5098)

C-16094 (12/5104)

Tumba 10:

(12/5128)

C-16108 (12/5130)

C-15920 (12/5131)

C-15992 (12/5132)

Tumba 16:

C-15919 (12/5240)

Tumba 22:

C-15838 (12/5205)

Tumba 26:

C-16114 (12/5256)

Tumba 29:

C-15828 (12/5261)

Tumba 31:

C-16217 (12/5279)

IIIa Terraza

Caverna VIII:

C-15985 (12/6576)

Recolección de superficie

C-15861 (12/8147)

C-15865 (12/8258)

C-15953 (12/8367)

C-15949 (12/8369)

(12/8376)
C-16194 (12/8355)

C-15923 (12/8149)

C-15960 (12/8152)

C-15878 (12/8373)

C-15864 (12/8147)

(12/8136)

C-15933 (12/8236)

C-16037 (12/8318)

(12/8232)

C-15956 (12/8144))

C-15939 (12/8236)

C-15947 (12/8239)

C-15952 (12/8240)

C-15922 (12/8197)

C-15942 (12/8139)

C-15940 (12/8142)

C-15947 (12/8239)

C-15899 (12/8357)

C-15970 (12/8234)

(12/8226)

C-15882 (12/8227)

C-15935 (12/8235)

C-16239 (12/8229)

C-15769 (12/8182)

C-15925 (12/8242)

Wari Kayan (Cerro Colorado) sin precisión del área
C-15939 (12/8236)
C-15921
C-15834
C-15928
C-15955
C-15910

Recepción: 4/VI/2018 Aceptación: 17/VII/2018 